\title{
Primal-dual approach to environmental Kuznets curve hypothesis: A demand and supply side analyses of environmental degradation
}

\author{
Gildas Dohba Dinga $^{1}$ (D) Dobdinga Cletus Fonchamnyo ${ }^{1}$ (D) Elvis Dze Achuo ${ }^{2}$ (D)
}

Received: 12 April 2021 / Accepted: 26 September 2021 / Published online: 14 October 2021

(c) The Author(s), under exclusive licence to Springer-Verlag GmbH Germany, part of Springer Nature 2021

\begin{abstract}
The unavoidable negative effects of global warming have been a key if not the most important issue occupying policy makers in the world at large today. The much talked about green economy nowadays seeks to achieve sustainable economic growth and development without compromising environmental quality. The relationship between environmental degradation and economic growth is largely explained by the environmental Kuznets curve (EKC) hypothesis. By employing the basic postulation of the baseline EKC framework, this study proposes and tests the existence of a dualistic approach of the EKC hypothesis. Geometry is used to illustrate the proposed dualistic model. Meanwhile, the novel dynamic common correlation effect econometric technique is employed to test the existence of the dualistic EKC within a panel of 109 countries from 1995 to 2016. The outcome from the estimated models shows that, in the global sample, the existence of the dualistic U-shaped and $\mathrm{N}$-shaped EKC hypothesis is validated. When the sample is split into subsamples based on income levels, the U-shaped EKC hypothesis is validated for lower-income and high-income economies meanwhile, the N-shaped dualistic EKC is mostly associated with high-income economies.
\end{abstract}

Keywords Environmental quality $\cdot$ Economic growth $\cdot$ EKC $\cdot$ Primal-dual approach

JEL Code $\mathrm{C} 01 \cdot \mathrm{C} 02 \cdot \mathrm{C} 33 \cdot \mathrm{Q} 56 \cdot \mathrm{Y} 10$

\section{Introduction}

In a bid to combat climate change, enhance economic prosperity, and attain the set goals of the 21 st Conference of the parties (COP21 hereafter), it is very important to comprehend the effects of variations in economic growth on the environment (Allard et al. 2018a). According to the IPCC (2014), continuous environmental degradation can lead to devastating consequences for humanity, with unavoidable effects like floods, droughts, adverse effects on growth,

Communicated by Eyup Dogan.

Gildas Dohba Dinga

gildoh1995@gmail.com

1 Faculty of Economics and Management Sciences, Department of Economics, The University of Bamenda, Bamenda, Cameroon

2 Faculty of Economics and Management Sciences, Department of Economics, The University of Dschang, Dschang, Cameroon health, and the destruction of ecosystems. According to goal number 13 of the United Nations Sustainable Development Goals-agenda 2030, emphasis is laid on the urgent need to take action towards combating climate change and its adverse impacts (UN 2015). This clarion call to combat the negative effects of climate change and reduce global warming has been topical in the recent Conferences of the Parties (COP22, COP23, COP24) due to the damaging effects of climate change to nature as well as mankind. This prompted many nations to agree on keeping the rise in global temperature well below $2{ }^{\circ} \mathrm{C}$.

The United Nations (2020) noted that although the COVID-19 outbreak may result in a $6 \%$ fall in greenhouse gas emissions in 2020, this will still fall short of $7.6 \%$ annual reduction in order to limit global warming to $1.5^{\circ} \mathrm{C}$. This is due largely to continuous investments in fossil fuels despite the recognition in policy circles and beyond that to avoid dangerous climate change, most fossil fuel resources will need to be "left in the ground" (Ibrahim et al. 2021). Climate change has exacerbated the frequency and severity of natural disasters, which affected more than 39 million 
people in 2018 (United Nations 2020). The UN Sustainable Development Goals emphasizes the need to promote sustained, inclusive, and sustainable economies aimed at creating decent jobs, ensuring progress and the improvement of living standard. Reconciling the desire of nations to achieve economic growth without degrading the environment has become one of the major issues economists and policy makers around the globe are faced with today.

This has promoted the debate on whether economic growth which is important for prosperity and wellbeing of the economy and its citizens in both advanced countries and developing economies will increase ecological problems and harm Mother Nature or the environment. This debate has been topical among economists and policy makers in the aftermath of the advent of the environment Kuznets curve (EKC) hypothesis developed in the early 1990s (Grossman and Krueger 1991; Beckerman 1992; Panayotou 1993). The EKC hypothesis posits that environmental degradation and income indicate an inverted $U$-shaped relationship, showing an increase in pollution at low income or output levels and a decrease in pollution at high income levels. This relationship is illustrated in Fig. 1.

From Fig. 1, we notice that as income increases from an initial low level, the rate of environmental degradation increases up to a maximum level. A further increase in income will be associated with a fall in environmental degradation (environmental improvement). This hypothesis has been investigated in different countries using different proxies to account for environmental quality or degradation with diverse outcomes. Equally, an amelioration to this hypothesis was proposed by De Bruyn et al. (1998). The authors noted that when income growth results to a fall in environmental pollution as proposed by Grossman and Krueger (1995), a point will be attained when growth in income will lead to an increase in environmental degradation again. According to these authors, this occurs when the composition and technical effects are overcome by the scale effect. The scale effect indicates how economic growth increases pollution through the scaling up of economic activities within economies. The technical effect captures the introduction of new environmental regulation, the influence of diffusion, and relocation of modern technology. Meanwhile, composition effect explains how growth in income will increase or decrease emission depending on whether high income will shift the economic structure toward less or more pollution sector. Hence, the authors posited an N-shaped relationship between environmental pollution and growth in income.

Investigating this aforementioned relationship has been recurrent in the past decade. Most studies have used different polluting greenhouse gases, with $\mathrm{CO}_{2}$ being predominantly used since the late 1990s (Ike et al. 2020; Ahmad et al. 2020; Al-mulali and Ozturk 2016; Balaguer and Cantavella 2016). Other greenhouse gases used include: sulfur dioxide $\left(\mathrm{SO}_{2}\right)$ emission (Akbostanc1 et al. 2009). Authors like Ulucak and Bilgili (2018), Altıntaş and Kassouri (2020), Aydin et al. (2019), and Ulucak and Apergis (2018) among others have noted the weaknesses of such measures of environmental quality. Recently, authors have prioritized the use of ecological footprint which is considered a broader measure of environmental degradation. As noted by Wackernagel

Fig. 1 Basic primal EKC

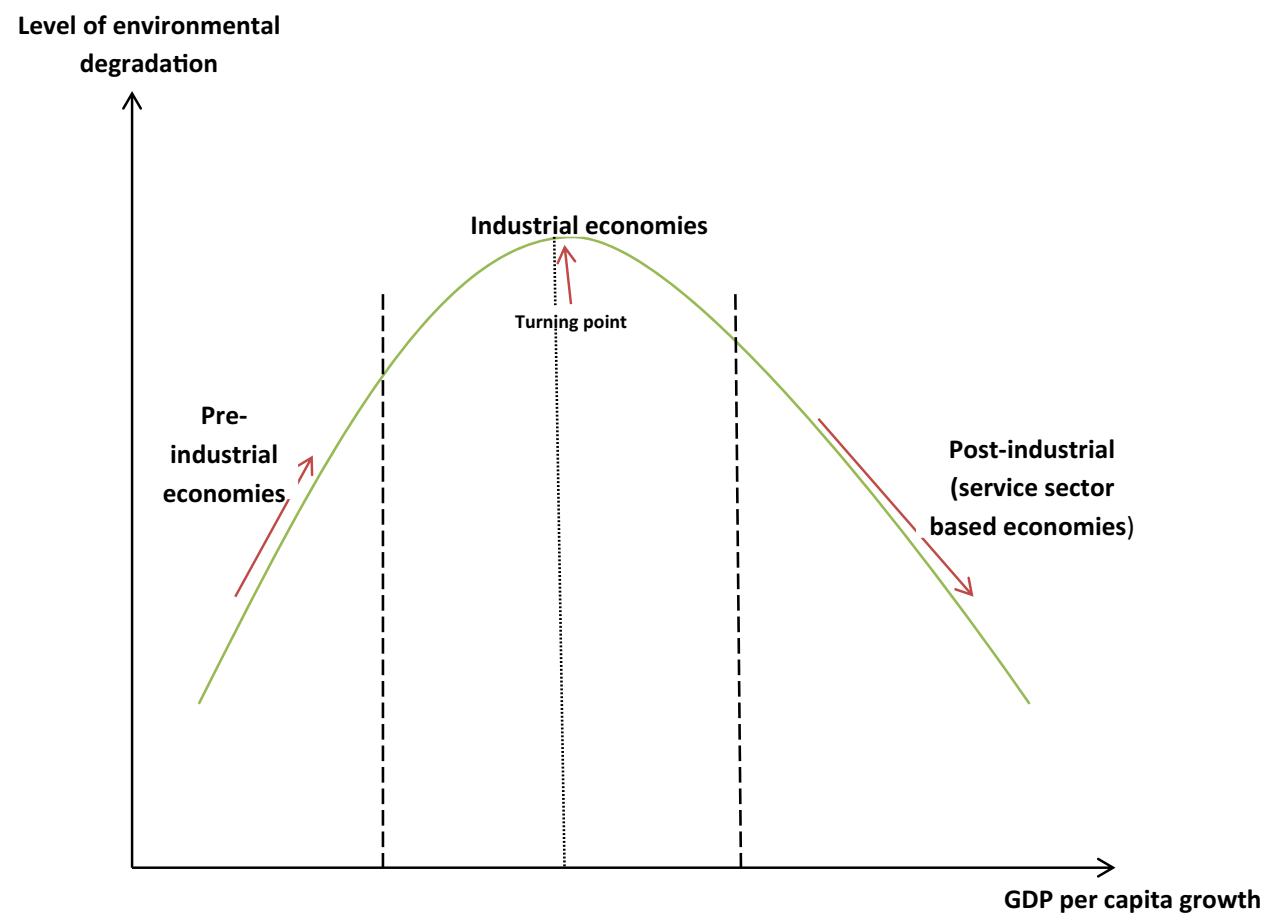


(2002), ecological footprint shows how much environment is demanded by people and how much biocapacity of Mother Nature is used up at a given time. The ecological footprint index accounts for cropland footprint, fishing ground footprint, build-up land footprint, grazing land footprint, and carbon footprint which is broader in scope than the frequently used greenhouse gases like $\mathrm{CO}_{2}$. Using the ecological footprint equally allows the use of people's ecological budget or nature regenerative capacity (biocapacity). McDonald and Patterson (2004) noted that the use of ecological footprint helps to emphasize the direct and indirect impacts of consumption and production activities on the environment.

The investigation of this relationship has been done using diverse empirical approaches. Most authors have turn to adopt conventional estimation techniques like the instrumental variable, mean group, pooled mean group, dynamic fixed effects, ordinary least square, generalized least square, and system and difference methods of moment techniques among others. These techniques have been a subject of criticism recently due principally to their inability to account for cross-sectional dependence (Ali et al. 2020; Arain et al. 2019; Neal 2015; Sarafidis and Wansbeek 2012). Since, shock in one country can affect other countries and the nonconsideration of such issues can lead to biased estimators.

In this study, we make use of the ecological footprint and available biocapacity to present a novel dualistic approach of investigating the EKC hypothesis. Our approach treats human extraction from nature as a demand side analyses meanwhile the remaining ecological-carrying capacity of the world at any given time is observed as the supply of nature to mankind at any given time. We employ geometry to illustrate the dynamic relationship that can exist between the available degree of usage of Mother Nature and the available stock that Mother Nature offers at a given time. This illustration is done with the introduction of a duality box. In the same vein, we use mathematical expressions and signs to provide an insight on how the existence of the dualistic approach can be validated. A panel of 109 countries based on data availability is used to empirically investigate the newly proposed dualistic analyses of the EKC hypothesis. For the empirical investigation, we adopt the novel dynamic common correlation effects (DCCE) technique proposed by Chudik and Pesaran (2015) due to the advantages it presents over conventional estimation techniques like the panel ordinary least square (OLS), dynamic OLS, fully modified OLS, system and difference generalized method of moments (GMM), pooled mean group, and panel smooth threshold regression technique among others.

The rest of the paper is organized as follows: The "Literature review" section provides a review of theoretical and empirical literature on the inverted U- and N-shaped EKC hypotheses. The "Methodological framework" section describes the data set and the estimation methodology used in the analyses. The "Results and discussion" section presents the empirical findings on the EKC. The last section provides the conclusion and policy recommendations.

\section{Literature review}

\section{Theoretical framework}

The Impact of Population, Affluence and Technology (IPAT) equation developed by Ehrlich and Holden (1971) is believed to be the first well-known work on environmental quality. The IPAT equation describes the relation between pollution, population growth, per capita income, and technology. Whence, the establishment of the Intergovernmental Panel on Climate Change in 1988 aroused research interest on the economic growth and environmental quality nexus thereby leading to the path-breaking work of Grossman and Krueger (1991). However, the theoretical basis in explaining the link between economic growth and environmental quality often makes reference to the EKC hypothesis, which was born in the early 1990s following the celebrated works of Grossman and Krueger (1991) and Shafik and Bandyopadhyay (1992). Nevertheless, the EKC is named after Simon Kuznets, who in 1955 first hypothesized that as an economy grows, income inequality initially increases and then falls after a threshold level of income (Kuznets 1955).

Hence, Grossman and Krueger (1991) posit that environmental degradation and income have an inverted U-shaped relationship, with pollution increasing with income at low levels of income and decreasing with income at high levels of income. This shows that there is an initial direct relationship between pollution and income and a subsequent indirect relationship at high-income levels, as shown in Fig. 1. We deduce from this position a new approach to this phenomenon by proposing that if at a given time $t$, the ecological asset (EA) of a given country or the world can be calculated, then this implies that the quantity of nature's ecological supply is known. Hence, nature's ecological asset supplies at time $t+1$ (EAS at time $t+1)$ will be the difference between nature's ecological asset at time $t$ and the total demand from $t$ to $t+1$. This can be represented mathematically as:

$\mathrm{EAS}_{\mathrm{t}+1}=\mathrm{EAS}_{\mathrm{t}}-\delta(\mathrm{EAD})$

where EAD denotes ecological assets demanded or used, EAS stands for ecological assets supplied, and $\delta(\mathrm{EAD})$ is the rate of degradation of the environment or environmental demand from period $t$ to period $(t+1)$. Hence, it can be deduced that at the initial low-income level of economic growth, there is a continuous fall in available biocapacity of a country up to a certain marginal level, but as the country moves to a high income level, there is improvement or 
increase in available biocapacity thereby showing an initial indirect relationship between available biocapacity and economic growth and a subsequent direct relationship as seen in Fig. 2.

Based on the primal EKC model proposed by Krugman and Gross and the corresponding dual model proposed in this study, it can be deduced that at a certain time $t+p$ if the total of nature's demand is equal to the total nature's supply at the period $t+(p-1)$ then, an environmental equilibrium is attained such that nature's supply is equal to nature's demand. This level of equality can be seen as the highest level at which societal demand from Mother Nature can be sustained (sustainably absorbed) by Mother Nature's supply. If at a given time $t+(p+1)$, EAS is less than EAD, then the country or the world at that level will be operating at a deficit. At this point, increase pressure on the environment will be met by increasing the negative effects (floods, plaque, hunger, and pandemics among others) on the society since the absorptive capacity of the country or the world is less than societal pressure (ecological degradation).

On the other hand, if at time $t+(p+1)$, EAS is greater than EAD, then societal rate of consumption of mother earth's resources falls below the absorptive capacity and mother nature will be able to limit the degree of the effect of environmental degradation. On a more specific note, it can be deduced that as human income or output rises while the rate of degradation is increasing, available absorptive capacity will be falling up to a certain level where the absorptive capacity will equal the rate of degradation. If after this point (overshoot day) economic growth continues to degrade the environment, then environmental deficit will be attained. This situation of deficit will be a springboard of the basic presentation on the dual relationship between environmental overshoot and environmental pollution, presented in Fig. 3 as the environmental duality box 1 .

From Fig. 3, the initial available earth biocapacity (overshoot value) is the distance $\mathrm{I}_{1}-\mathrm{C}_{1}$. From the demand side, as economic growth increases from $\mathrm{I}_{1}$ to $\mathrm{I}_{2}$, human demand of nature (ecological footprint) rises to point $b$ and the area $I_{1}-b_{1}-I_{2}$ is the level of degradation of nature to attain the desired income $I_{2}$. Equally, from the supply side, due to the increase in human activity to attain the growth point $\mathrm{I}_{2}$, available earth biocapacity drops by the area $\mathrm{C}_{1}-\mathrm{a}_{1}-\mathrm{C}_{2}$. Since at this point ecological overshoot is still greater than ecological footprint, the world will be operating at an ecological surplus represented by the area $a_{1}-e_{1}-b_{1}$. Note that at this level, available environmental quality falls from the initial point $I_{1}-C_{1}$ to $a_{1}-b_{1}$. As countries continue to move to higher income levels, available biocapacity continue to reduce. At income level $\mathrm{I}_{3}$, the supply of nature is equal to demand and hence the overshoot day is attained. The line A-B is the overshoot day line and $e_{1}$ is the point of the overshoot day. This is the point where the distinctive analysis of our proposed environmental duality boxes $1,2,3$, and 4 differs.

Figure 3 presents a scenario whereby as per capita income increases from $\mathrm{I}_{3}$ to $\mathrm{I}_{4}$, the overshoot curve continues to fall up to point $\mathrm{a}_{2}$ for the supply side meanwhile the demand side curve continues to rise up to point $\mathrm{b}_{2}$. At income level $\mathrm{I}_{4}$, the world will be operating at an ecological deficit since nature demand (EF) is greater than nature supply (EOS). This deficit is represented by the distance $b_{2}-e_{3}-a_{2}$. If the situation is not addressed through global-oriented policies and the EOS curve continues to fall up to point $\mathrm{I}_{5}$, EF will equally attain point $\mathrm{C}_{5}$. At this point, there will be a disaster given that the world's absorptive capacity of pollution will be zero and all of what nature offers must have been exhausted. The

Fig. 2 Basic dual EKC

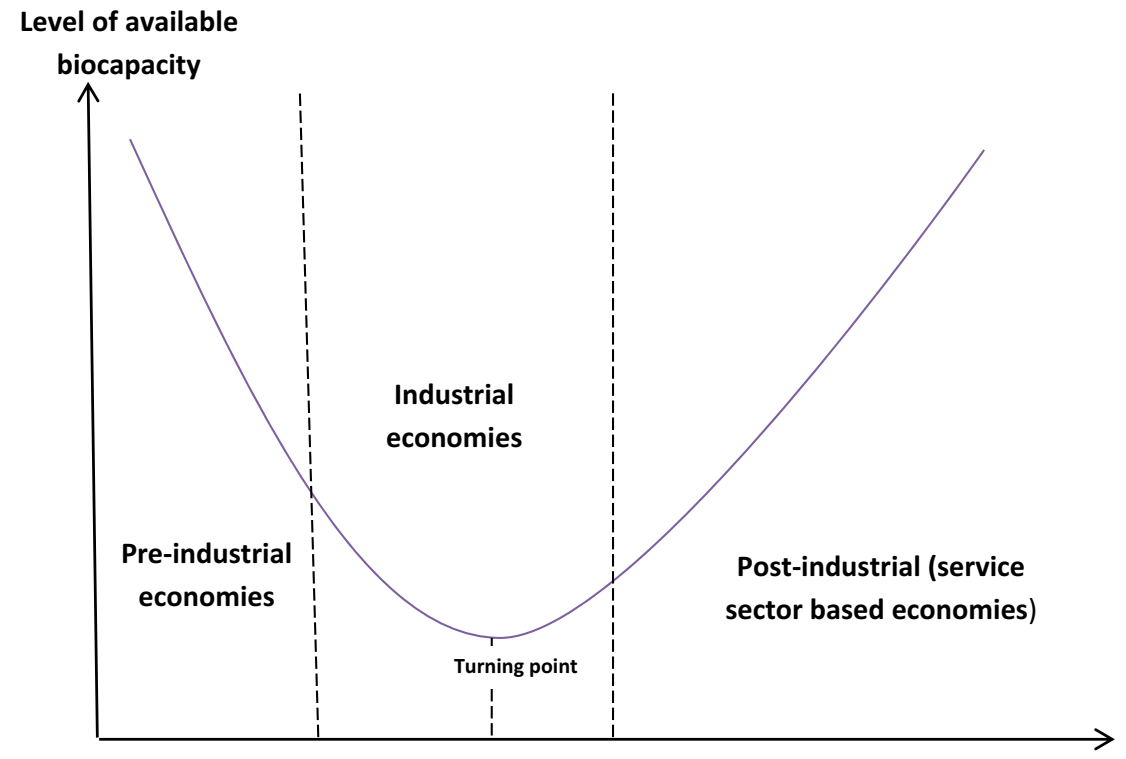

GDP per capita growth 
Fig. 3 Environmental duality box 1

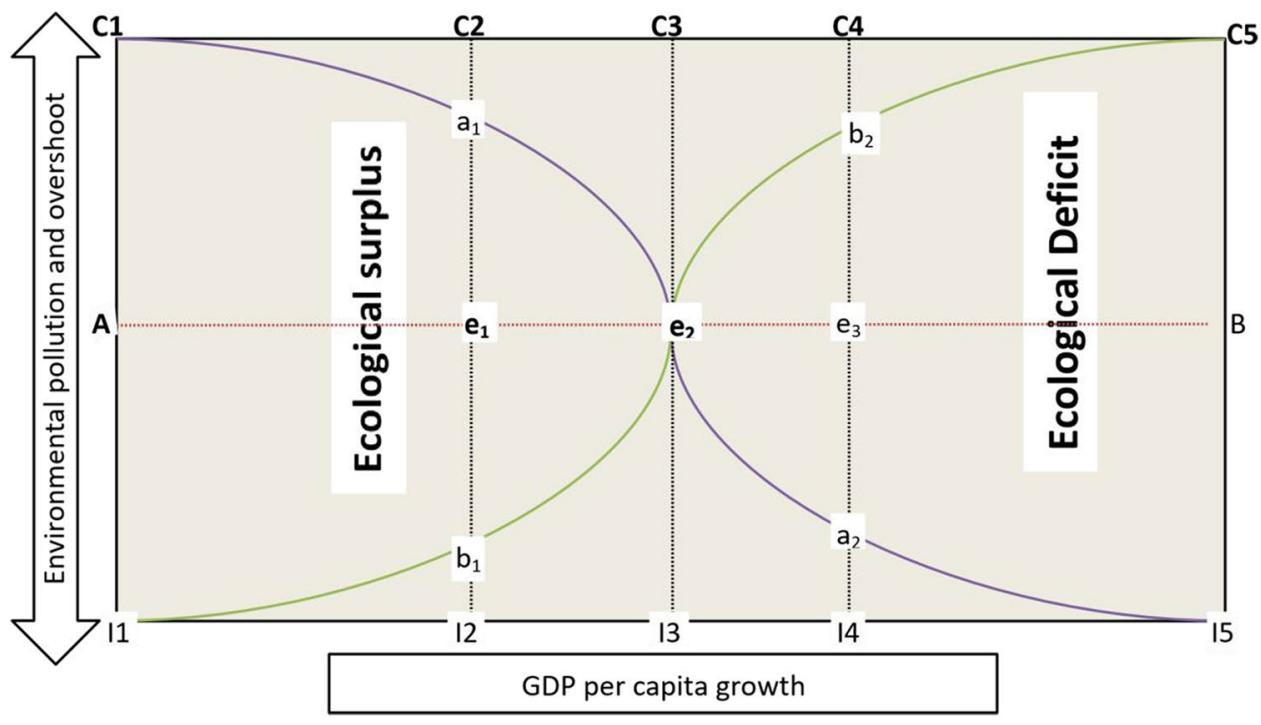

scenario presented by the area $C_{5}-b_{2}-e_{2}-a_{2}-I_{5}$ is one that the sustainable development goals are systematically seeking to avoid in the future and global consensus is imperative since this scenario will possibly bring chaos to the world.

The environmental duality box 2 presented in Fig. 4 shows a scenario that explains the basic EKC hypothesis within a dualistic framework. The dualistic relationship presents a situation whereby as economic growth increases consistently from point $\mathrm{I}_{1}$ up to point $\mathrm{I}_{3}$, EF or nature demand increases up to point $\mathrm{e}_{2}$ and the supply of nature (EOS) falls from $\mathrm{C}_{1}$ to $\mathrm{e}_{2}$. At this point, $\mathrm{EF}=\mathrm{EOS}$ and the earth absorptive capacity is at its maximum and the overshoot day is reached. As income increases from $\mathrm{I}_{3}$ to $\mathrm{I}_{4}, \mathrm{EF}$ rather begins to fall consistently from $e_{2}$ to $b_{2}$ and pollution is reduced by the area $e_{2}-e_{3}-b_{2}$. In the same rationale from $\mathrm{e}_{2}$, EOS starts rising due to improvement in positive environmental policy implementations, thereby creating a new surplus of Mother Nature. The gain or improvement of the environment is indicated by the area $e_{2} a_{2} b_{2}$. Such a feat can be attained if there is the development of environmentally friendly technologies, efficiency in the use of available resources among others. The rise and fall of the EF curve from $\mathrm{I}_{1}-\mathrm{e}_{2}-\mathrm{I}_{5}$ presents an illustration of the EKC hypothesis. Conversely, the fall and rise of the EOS from $\mathrm{C}_{1}-\mathrm{e}_{2}-\mathrm{C}_{5}$ presents the dual version of the primal EKC model proposed by Grossman and Krueger (1995).

Authors like De Bruyn et al. (1998) argued that an $\mathrm{N}$-shaped EKC can occur given that when environmental degradation starts decreasing with an increase in income, beyond a certain income level, increase in income will again lead to an increase in environmental degradation. Torras and Boyce (1998) highlighted that such a scenario is possible if the scale effect overcomes the composition
Fig. 4 Environmental duality box 2

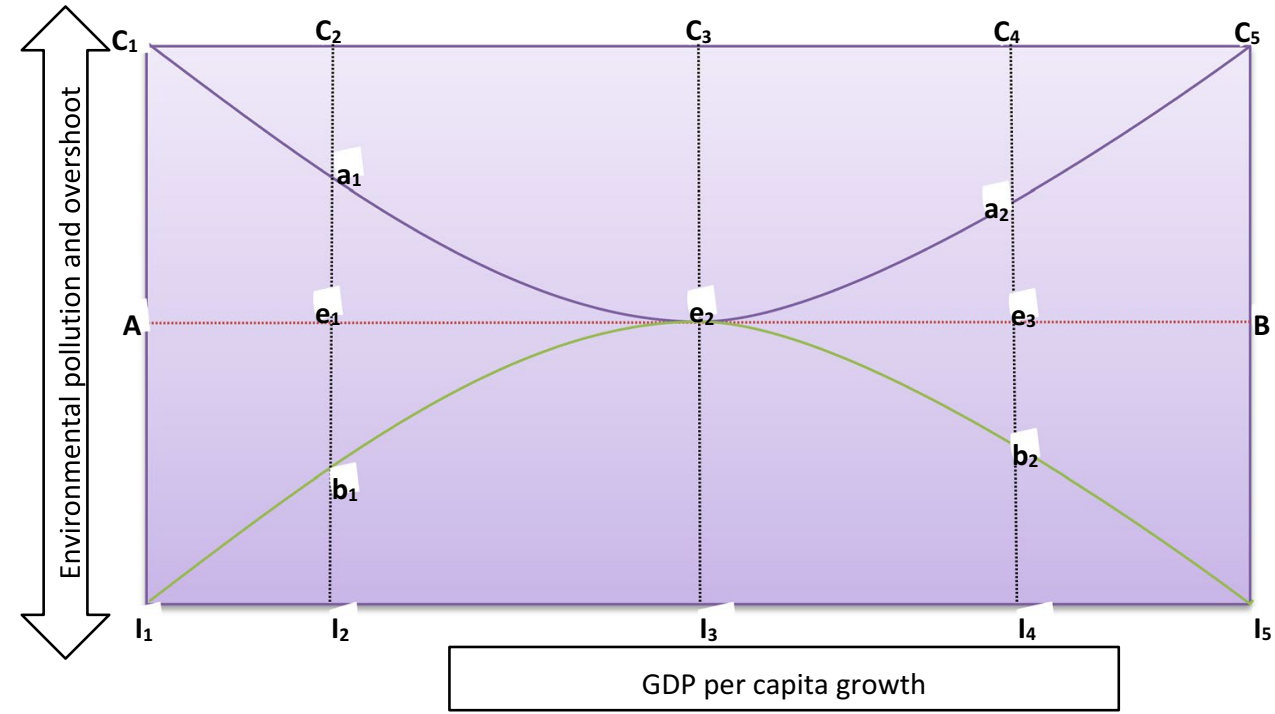


and technical effects. We equally present a dualistic framework to the $\mathrm{N}$-shaped EKC hypothesis.

From the duality box 3 presented in Fig. 5, as income increases from $\mathrm{I}_{1}$ to $\mathrm{I}_{3}$, ecological footprint increases from $I_{1}$ through $b_{1}$ to point $e_{2}$ and ecological overshoot falls from $\mathrm{C}_{1}$ through $\mathrm{a}_{1}$ to $\mathrm{e}_{2}$. At this point, the $\mathrm{C}_{1}-\mathrm{I}_{1}-\mathrm{e}_{2}$ area has been consumed from nature and EF equals EOS hence the earth's absorptive capacity is zero. Due to changes in technology and the adoption of environment-friendly policies, as income increases from $I_{3}$ to $I_{4}$, EF falls to $b_{2}$ and EOS increases to $a_{2}$ creating an ecological surplus of $a_{2}-b_{2}$ and the total area $\mathrm{e}_{2}-\mathrm{a}_{2}-\mathrm{b}_{2}$ of societal environment is improved. Subsequently, as income increases from $\mathrm{I}_{4}$ to $\mathrm{I}_{5}$, the scale effect overcomes the composition and technical effects and EF starts increasing from $b_{2}$ to $b_{3}$, meanwhile EOS falls from $a_{2}$ to $a_{3}$. The movement of the EF curve through $\mathrm{I}_{1}-\mathrm{b}_{1}-\mathrm{e}_{2}-\mathrm{b}_{2}-\mathrm{b}_{3}$ indicates the $\mathrm{N}$ shape of the EKC proposed by authors like De Bruyn et al. (1998). Whence, the movement of the EOS curve through $\mathrm{C}_{1}-\mathrm{a}_{1}-\mathrm{e}_{2}-\mathrm{a}_{2}-\mathrm{a}_{3}$ indicates the dual analyses of the $\mathrm{N}$-shaped EKC hypothesis proposed in this study.

Figure 6 presents a similar scenario as in Fig. 5 but for the fact that there is a twofold movement before the turning of the $\mathrm{N}$-shape is produced and convergence occurs after deficit. From Fig. 6, as income increases from $\mathrm{I}_{1}$ to $\mathrm{I}_{2}, \mathrm{EF}$ increase from $I_{1}$ to $e_{1}$ leading to a fall of EOS from $C_{1}$ to $\mathrm{e}_{1}$. At this point, $E O S=E F$ but as income increases from $I_{2}$ to $I_{3}$, EF continues to rise up to $a_{1}$ while EOS continues to fall to $b_{1}$ thereby creating an ecological deficit of $e_{1}-a_{1}-b_{1}$. But as income increases from $\mathrm{I}_{3}$ to $\mathrm{I}_{4}$, with the implementation of positive environmental policies, EF starts falling
Fig. 5 Environmental duality box 3

Fig. 6 Environmental duality box 4
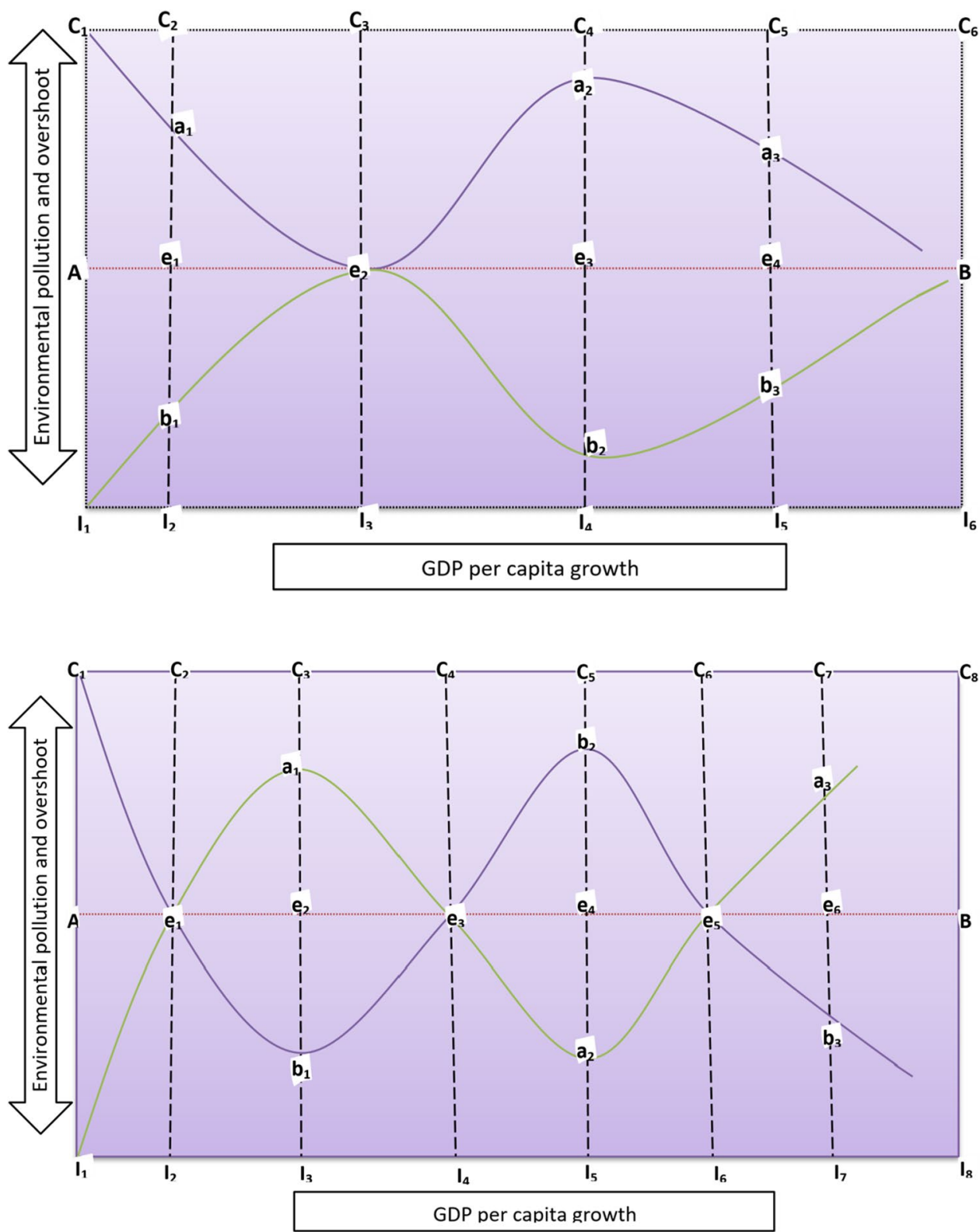
while EOS starts rising up to $\mathrm{e}_{3}$. Here, the initial ecological deficit created is reduced to zero and $\mathrm{EF}=\mathrm{EOS}$. As income increases from $\mathrm{I}_{4}$ to $\mathrm{I}_{5}$, there is continues increase in EF to $b_{2}$ while EOS continues to fall to $a_{2}$ thereby creating an ecological surplus indicated by the area $\mathrm{e}_{3}-\mathrm{b}_{2}-\mathrm{a}_{2}$. Equally, as growth increases from $\mathrm{I}_{5}$ to $\mathrm{I}_{7}$, the scale effect overcomes the composition and technical effects and EF starts increasing again while EOS starts falling leading to a reduction in the initial surplus created to zero at point $\mathrm{e}_{5}$ and a subsequent deficit after this point. In a world where many countries have already reached their overshoot day and with continuous increase in globalization, such a twofold convergent is equally possible due to interdependence between states. This is another version to explain the $\mathrm{N}$-shaped EKC which has not been considered in the literature but there is a possibility of attaining such feat within nations in the world today given that with globalization, deficit in one country can be reduced by another since a positive environmental policy in a country can possibly have a spillover effect in another. This presents the undulating trend of the ecological indicators of the primal-dual analyses.

The above paragraphs summarize the novel primal-dual approach to EKC analyses that this study uses to explain the effect of growth on environmental quality and sustainability. Such appraisal will indicate how human activities through growth pollute the environment and equally how it can increase or decrease available capacity of Mother Nature on earth.

\section{Empirical literature}

Generally, from a review of the existing literature on the EKC hypothesis and the empirical investigations done this far in examining the dualistic approach proposed in this study, one would conclude without bias that existing studies have been principally based on the demand side analyses. Among the existing empirical works, Altıntaş and Kassouri (2020) estimated a heterogeneous panel model of 14 European countries from 1990 to 2014 and concluded that the ecological footprint is an appropriate environmental tool that fits the EKC prediction in contrast to $\mathrm{CO}_{2}$ emissions. They equally highlighted that the EKC is sensitive to the type of environmental degradation proxy used. On their part, Ahmad et al. (2020) using the Driscoll-Kraay standard error pooled ordinary least square method on a sample of 90 belt and cross road countries and concluded on an inverted U-shape between economic growth and $\mathrm{CO}_{2}$ emissions. Beyene and Kotosz (2019) employed the pooled mean group technique in a panel of 12 East African countries and verified the existence of a short-run U-shaped EKC and a long-run bell-shaped EKC.

While re-assessing the relationship between economic growth and pollution emissions $\left(\mathrm{CO}_{2}\right)$, Khan and Eggoh
(2020) employed the panel smooth threshold regression (PSTR) technique in a panel of 146 countries from 1990 to 2016 and concluded on the existence of the EKC hypothesis on the global panel and the income-specific subsamples. Naqvi et al. (2020) employed the common correlated effect of mean group and augmented mean group on a panel of 155 countries from 1990 to 2017 and examined the relationship between economic growth per capital, renewable energy, financial development, and ecological footprint. While they concluded on the validity of the EKC hypothesis for high-income countries, their results for other income groups where not reliable. Conversely, the EKC hypothesis was invalidated for a panel of 20 Latin American and Caribbean countries (Jard ó $\mathrm{n}$ et al., 2017) and 15 EU countries (Armeanu et al., 2018). However, Allard et al. (2018) sought to examine the $\mathrm{N}$-shaped EKC in a panel of 74 countries from 1992 to 2012 using $\mathrm{CO}_{2}$ emissions as a measure of environmental degradation. The $\mathrm{N}$-shaped EKC hypothesis is validated in their study for all income levels except for the upper middle income countries. The $\mathrm{N}$-shaped EKC hypothesis has equally been confirmed by Özokcu and Özdemir (2017) for a sample of 26 OECD with the help of the Driscoll-Kraay Standard Errors technique. Using a panel of 28 OECD countries, Álvarez et al. (2015) employed the generalized least square to affirm the existence of the $\mathrm{N}$-shaped EKC. In the same vein, Friedl and Getzner (2003) used the pooled OLS and concluded on the existence of an $\mathrm{N}$-shaped EKC for Austria.

Unlike the preceding studies that have explored the nexus between national income growth and environmental quality (Ahmad et al. 2020; Khan and Eggoh 2020; Dinda 2005; Beyene and Kotosz 2019), several recent studies have considered the role of urbanization, FDI and ICTs on environmental degradation (Abbasi et al. 2020; Teng et al. 2021; Bakhsh et al. 2021; Chen et al. 2019; Wang et al. 2019). Yet, others have questioned the role of institutional quality, education, and inclusive human development on environmental quality (Mehmood 2021; Haldar and Sethi 2021; Dogan and Kirikkaleli 2021). For instance, Abbasi et al. (2020) affirm that urbanization has a significant positive impact on $\mathrm{CO}_{2}$ emissions, implying that urban development constitutes speed-brakes to environmental sustainability. This result corroborates earlier findings by Zhang et al. (2017) asserting that urbanization increases $\mathrm{CO}_{2}$ emissions. However, Zhang et al. (2017) conclude that beyond a threshold of about $73.80 \%$, urbanization tends to improve environmental quality, implying the existence of an inverted U-shaped relation between urbanization and $\mathrm{CO}_{2}$ emissions. Nevertheless, the authors caution that excessive urbanization is harmful to environmental quality.

Withal, there has been little or no consensus among the numerous scholars who have sought to investigate the inverted U- or N-shaped EKC hypothesis. Methodological 
issues have equally been of a major concern since most of the aforementioned studies have focus on conventional estimation techniques that does not account for cross country or intercountry dependence. Moreover, focus has been predominantly devoted towards the demand side analyses with little or no effort made as regards the supply side (available biocapacity). It is within the backdrop of this gap in literature and quantitative approach that this study sought to propose a dual hypothetical analysis of the EKC phenomenon.

\section{Methodological framework}

\section{Data description}

In order to verify the proposed primal-dual EKC hypothesis in this study, data were collected from two principal sources that is the world development indicators (WDI) and the Global Footprint Network (GFN) data bases spanning from 1995 to 2016 for a total sample of 109 countries (see Table 1). The study period is chosen based on data availability. While data for ecological footprint and ecological biocapacity were obtained from the GFN, data for economic growth per capita and other explanatory variables are obtained from the WDI database. The description of these variables can be found in Table 2 .

\section{Modelling framework}

In order to examine the dualistic type analyses of the environmental problem, we construct two nonlinear models that simultaneously explain the demand and the supply side analyses. The baseline model proposed is given as:

$\mathrm{Y}=\alpha_{1} \mathrm{X}+\alpha_{2} \mathrm{X}^{2}$

$\mathrm{W}=\beta_{1} \mathrm{X}+\beta_{2} \mathrm{X}^{2}$

Equations (2) and (3) present the basic model of our dualistic approach to EKC analyses. From the two models, Eq. (2) denotes the demand side analyses that give the baseline model proposed by Grossman and Kreuger (1991) meanwhile we propose Eq. (3) as a supply side dual model of the basic primal model proposed by Grossman and Kreuger (1991). Y, X, and W respectively denotes ecological footprint, economic growth per capita, and ecological overshoot. The following analyses can be made from these equations. From Table 3, if the coefficients of Eqs. (1) and (2) verify case 1 hypotheses, then there is no ECK curve and the dual relation shows continues pollution of the environment from the demand side and the continuous reduction of Mother Earth's biocapacity, which is shown in Fig. 1. This shows a situation wherein, economic agents and policy
Table 1 Countries considered

\begin{tabular}{|c|c|c|c|}
\hline $21 \mathrm{LIC}$ & Comoros & Armenia & Turkey \\
\hline Benin & Congo. Rep & Azerbaijen & 24 HIC \\
\hline Burkina Faso & Cote d'Ivoire & Belarus & Australia \\
\hline Burundi & Egypt & Botswana & Bahamas \\
\hline Central African & El Salvador & Brazil & Bahrain \\
\hline Chad & Eswatini & Bulgaria & Chile \\
\hline Congo. Dem. Rep & Ghana & China & Croatia \\
\hline Gambia & Honduras & Colombia & Czech Republic \\
\hline Guinea & India & Costa Rica & Denmark \\
\hline Guinea-Biseau & Indonesia & Ecuador & Hungary \\
\hline Madagascar & Kenya & Gabon & Israel \\
\hline Malawi & Kyrgyz Republic & Guatemala & Japan \\
\hline Mali & Moldova & Guyana & Korea, Rep \\
\hline Mozambique & Mongolia & Jamaica & New Zealand \\
\hline Nepal & Morocco & Jordan & Norway \\
\hline Niger & Nicaragua & Kazakhstan & Oman \\
\hline Rwanda & Nigeria & Lebanon & Panama \\
\hline Sierra Leone & Pakistan & Malaysia & Poland \\
\hline Tajikistan & Philippines & Mauritius & Qatar \\
\hline Tanzania & Senegal & Mexico & Saudi Arabia \\
\hline Togo & Sudan & Namibia & Singapore \\
\hline Uganda & Tunisia & Paraguay & Sweden \\
\hline $31 \mathrm{LMIC}$ & Ukraine & Peru & Switzerland \\
\hline Angola & Vietnam & Romania & UK \\
\hline Bangladesh & Zimbabwe & Serbia & USA \\
\hline Bhutan & 33 UMIC & South Africa & Uruguay \\
\hline Bolivia & Albania & Sri Lanka & \\
\hline Cambodia & Algeria & Thailand & \\
\hline Cameroon & Argentina & Tonga & \\
\hline
\end{tabular}

makers are still to consider the negative effects of pollution to the environment and as such, they continue production without a clear-cut cleaning policy in place. On the other hand, case 2 indicates that ecological footprint increases as income increases, reaches a maximum and then starts falling (EKC hypothesis) while the ecological overshoot falls and reaches a certain minimum and then starts to rise (dual of the primal EKC model). This demand side and supply side type analyses is illustrated in Fig. 2. Here, environmental cleaning policies are adopted and at a certain level further increase in income is accompanied with fall in pollution and increase in biocapacity.

In order to equally examine the $\mathrm{N}$-shaped ECK model and equally deduce it corresponding dual-supply side shape, we examine the following relation:

$\mathrm{Y}=\alpha_{1} \mathrm{X}+\alpha_{2} \mathrm{X}^{2}+\alpha_{3} \mathrm{X}^{3}$

$\mathrm{W}=\beta_{1} \mathrm{X}+\beta_{2} \mathrm{X}^{2}+\beta_{3} \mathrm{X}^{3}$ 
Table 2 Description of variables and descriptive statistics

\begin{tabular}{|c|c|c|c|c|c|c|}
\hline Variables & Description & Obs & Mean & Std.Dv & Min & Max \\
\hline EFP & Ecological footprint (GFN) & 2398 & 2.827 & 2.238 & 0.481 & 16.965 \\
\hline EOS & Ecological overshoot (GFN) & 2398 & .937 & 7.975 & -14.856 & 69.202 \\
\hline GDP & GDP growth rate per capita (WDI 2019) & 2420 & 2.433 & 4.13 & -36.557 & 37.536 \\
\hline GDP2 & The square of GDP per capita & 2420 & 22.97 & 64.152 & 1336.40 & 1408.916 \\
\hline GDP3 & The cube of GDP per capita & 2420 & 121.18 & 1922.335 & $-48,854.57$ & $52,884.402$ \\
\hline DINV & Gross domestic fixe capital formation \% of GDP (WDI 2019) & 2420 & 22.47 & 7.541 & -2.424 & 68.023 \\
\hline FDI & Net foreign direct investment inflow \% of GDP (WDI 2019) & 2420 & 3.892 & 5.372 & -37.155 & 57.838 \\
\hline POP & Annual population growth rate (WDI 2019) & 2420 & 1.645 & 1.47 & -3.848 & 17.511 \\
\hline
\end{tabular}

Obs, number of observations; Std.dv, standard deviation; Min, minimum value; Max, maximum value

Table 3 Sign analyses of the demand side and supply side approach of EKC

\begin{tabular}{|c|c|c|c|c|c|c|c|}
\hline Case 1 & $\alpha 1>0$ & $\alpha_{2}>0$ & $\beta_{1}<0$ & $\mathrm{~B}_{2}<0$ & & & No dual U/n-shaped EKC \\
\hline Case 2 & $\alpha_{1}>0$ & $\alpha_{2}<0$ & $\beta_{1}<0$ & $\mathrm{~B}_{2}>0$ & & & Dual U/ח-shaped EKC \\
\hline Case 3 & $\alpha_{1}>0$ & $\alpha_{2}<0$ & $\alpha_{3}>0$ & $\beta_{1}<0$ & $\beta_{2}>0$ & $\beta_{3}<0$ & Dual N-shaped EKC \\
\hline Case 4 & $\alpha_{1}>0$ & $\alpha_{2}>0$ & $\alpha_{3}<0$ & $\beta_{1}<0$ & $\beta_{2}<0$ & $\beta_{3}>0$ & No N-shaped EKC but U-shaped \\
\hline Case 5 & $\alpha_{1}>0$ & $\alpha_{2}<0$ & $\alpha_{2}<0$ & $\beta_{1}<0$ & $\beta_{2}>0$ & $\beta_{3}>0$ & No N-shaped EKC but U-shaped \\
\hline
\end{tabular}

Equation 4 presents the primal of the N-shaped EKC hypothesis meanwhile Eq. (5) gives the dual hypothesis we propose from the primal hypothesis. We make two possible analyses from these relations. Table 3 shows the variation of the different coefficients of the relation. Firstly, case 3 indicates that $\mathrm{EF}$ first increases, attains a maximum, begins to fall, attains a minimum, and then starts to increase. This explains the N-shaped EKC hypothesis as shown in Fig. 3. Looking at the dualistic model we present, ecological overshoot (EOS) initially falls, reaches a minimum, tends to increase to a certain maximum, and begins to fall again. This indicates that as policy makers implement environmentally friendly policies within a nation due to the negative effects of past degradation, when environmental improvement is attained up to a certain level, economic agents tend to lose focus on combating pollution and as such pollution starts increasing again. We further present another version of the $\mathrm{N}$ shape in case 4 wherein EF increases as EOS falls, attains a certain point of inflexion, after which it continues to increase while EOS equally continues to fall. The EF increases, attains another marginal level and starts to fall while the EOS continues to fall, attains the next marginal level, and starts to increase. This scenario rather validates a long run convergence $\mathrm{U}$-shaped EKC, as the $\mathrm{N}$-shaped dual analysis is rejected while the $\mathrm{U}$ shape is accepted.

Case 5 presents a scenario wherein, EF increases, attains a certain marginal level, and starts falling and continues to fall in the next marginal level. Meanwhile, EOS decreases up to a certain marginal level and starts increasing. This rejects the $\mathrm{N}$ shape and rather validates the $\mathrm{U}$-shaped EKC. Here, economic agents after realizing the negative effects of environmental degradation, put in place appropriate abatement policies and continue to implement these policies thereby achieving a better environment. Cases 4 and 5 present another version of the U-shaped EKC which is rarely discussed or analyzed in the existing literature but shows a possible policy outcome of the income/environmental relation.

\section{Empirical model and estimation technique}

From the baseline model framework, we estimate a dynamic model. The estimated model is inspired from the model proposed by authors like Grossman and Kreuger (1991), De Bruyn et al. (1998), Altıntaş and Kassouri (2020), and Khan and Eggoh (2020) among others. The model can be specified as follows;

$Y_{i t}=\varnothing_{i}+\vartheta Y_{i t-1}+\alpha 1 X_{i t}+\alpha 2 X_{i t}^{2}+\alpha 3 X_{i t}^{3}+\lambda Z_{i t}+\gamma_{i} f_{t}+\xi_{\mathrm{it}} Y_{i t}$

$W_{i t}=\varphi i+\rho W_{i t-1}+\beta_{1} X_{i t}+\beta_{2} X_{i t}^{2}+\beta_{3} X_{i t}^{3}+\delta Z_{i t}+\gamma_{i} f_{t}+\xi_{i t}$

where $\vartheta, \rho, \alpha_{1}, \alpha_{2}, \alpha_{3}, \lambda, \beta_{1}, \beta_{2}, \beta_{3}$, and $\delta$ in Eqs. (6) and (7) are the parameters of the demand side and the supply side model to be estimated which are bounded by a finite constant and homogenous over cross-sectional units $i$. $Z$ is a set of exogenous variables which in this study, we consider variables like FDI, domestic investment, and population growth. As noted by Gareth (1968), within a free economy wherein individuals pursue their best interest, the destination of such economy is ruin. This implies that environmental 
pollution arises due to deficiency of accountability by economic agents via their production and consumption drive vis-à-vis third parties which are obliged to live with such degraded environment, in this light, human quest to accumulate capital be it domestic or foreign will significantly affect it immediate environment. $i$ denotes the individual unit (country) and $t$ the year. $f_{t}$ denotes an unobserved common factor with heterogeneous factor loadings, and $\gamma_{i}$ and $\xi_{i t}$ are the idiosyncratic error terms.

We employ the novel dynamic common correlation technique proposed by Chudik and Pesaran (2015). This technique is adopted because of its novelty and the ability for the approach to account for cross-sectional dependence. The nonconsideration of cross-sectional dependence by conventional estimation techniques has been identified by different authors as a source of biasness in estimation (Ali et al. 2020; Dinga et al. 2020; Neal 2015). With the high degree of globalization in the world today, the interdependence between states has heightened tremendously, implying that empirical analyses that do not account for such interdependence will be biased. Within the framework of this study, considering that cross-sectional dependence is very vital, economies with high level of pollution and where EF is already showing trends of surpassing the EOS can always pay low polluters with much more available biocapacity to conserve or to reduce their level of pollution so as to serve as a balance in the deficit in their respective countries. Such interdependence between environmental debtors and creditors has been a key way to maintain global pollution levels.

Before proceeding to estimate the different models, we first check our data for cross-sectional dependence since this will help select appropriate estimation techniques and to choose between first- or second-generation tests. The Pesaran (2004) cross-sectional dependence test and the Pesaran (2015) cross-dependence test are employed in this study. To ensure that our model does not suffer from spurious regression, we test our database for unit root test. We employ the second-generation unit root test proposed by Pesaran (2003) CADF test and the Pesaran (2007) CIPS unit root test that accounts for cross-sectional dependence. Slope homogeneity in panel data analyses has been highlighted as a key issue to address. Breitung (2005) noted that crosssectional dependence implied countries have similarities in development and as such ensuring cross-sectional heterogeneity is vital for robust estimations. The most recent slope heterogeneity test by Pesaran and Yamagatta (2008) that is an ameliorated version of that proposed by Swamy (1970) is adopted in this study. After taking into consideration the issue of slope homogeneity, we proceed to examine the panel for cointegration in order to establish the existence of a long-run relationship. The Westerlund (2007) second-generation cointegration test that considers cross-sectional dependence is adopted in this study. After ensuring the panel is free from all the aforementioned issues that could bias the estimations and make them untrustworthy for inference, we proceed to estimate our dualistic models using a nonlinear DCCE approach. Another key advantage of the DCCE technique is the ability to correct for small sample bias (Ditzen 2016). The recursive mean technique of correcting small sample bias is adopted in this study. The data are compiled with the help of Microsoft excel and analyzed with STATA 14 software.

\section{Empirical results and discussions}

\section{Descriptive statistics}

Based on the results of the basic statistics of the variables considered shown in Table 2, the average performance of ecological footprint is 2.827 with a standard deviation of 2.238 and a minimum and maximum score of 0.481 and 16.965, respectively. This shows that the level of EF of the sample at large has been relatively large and rarely deviates above the average of the world. On the other hand, ecological overshoot indicates a mean, standard deviation, minimum and maximum value of $0.937,7.975,-14.865$, and 69.202 , respectively. This implies that EOS is slightly positive on average within the sample and greatly deviates from the mean. The minimum value is indicative of how some countries are already ecological debtors entailing that some economies within the sample are already consuming more than Mother Nature carrying capacity of their country. In the same vein, the average GDP for countries within the sample stood at 2.433 with standard deviation of 4.13 and a maximum and minimum value of -36.557 and 37.536 respectively for countries considered. This shows that the growth of GDP per capital greatly deviated above the mean during the study period and equally indicates negative growth rate of some economies. Equally, DINV, FDI, and POP for the global sample of 109 countries within the period under study were $22.47,3.892$, and 1.645 with standard deviations of $4.13,7.541,5.372$, and 1.47 , respectively. The result shows that deviation from the mean of growth per capital has been higher within the selected countries. Growth rate per capital has shown a negative value implying that at least for some countries, negative growth was noticed. Same holds for DINV, FDI, and POP.

\section{Cross-sectional dependence and unit root test}

With the advent of globalization, cross-sectional dependence has become a vital component to consider when dealing with panel data analyses. This is due to the fact that the nonaccounting of spillover effects of shocks from one country to another can lead to bias estimates and misleading 
inference. Cross-sectional dependence equally permits us to make a choice between first- or second-generation tests. In this study, we employ the Pesaran (2004) and Pesaran (2015) cross-sectional dependence test.

The results presented in Table 4 indicate that the null hypothesis of cross-sectional independence for the Pesaran (2004) test is rejected at the $1 \%$ significance level for all the variables of the study. This shows that there is strong presence of cross-sectional dependence. In the same vein, the null hypothesis of weak cross-sectional dependence for the Pesaran (2015) test is rejected at the $1 \%$ significance level thereby confirming cross-sectional dependence for all the variables.

After confirming the presence of cross-sectional dependence, we then examine the stationarity of the different variables. With the strong confirmation of cross-sectional dependence, we make use of two versions of second-generation unit root test, that is the CADF and CIPS test proposed by Pesaran in 2003 and 2007, respectively. From the panel unit root test result presented in Table 5, the null hypothesis

Table 4 Cross-sectional dependence test

\begin{tabular}{lccccc}
\hline Variables & \multicolumn{2}{c}{ Pesaran (2004) CD test } & & \multicolumn{2}{c}{ Pesaran (2015) CD test } \\
\cline { 2 - 3 } \cline { 5 - 6 } \cline { 5 - 6 } & CD-statistics & $P$-value & & CD statistics & $P$-value \\
\hline EFP & $16.300 * * *$ & 0.000 & & $354.554 * * *$ & 0.000 \\
EOS & $108.890 * * *$ & 0.000 & & $43.719 * * *$ & 0.000 \\
GDP & $42.380 * * *$ & 0.000 & & $136.451 * * *$ & 0.000 \\
GDP2 & $13.960 * * *$ & 0.000 & & $161.088 * * *$ & 0.000 \\
GDP3 & $27.490 * * *$ & 0.000 & & $68.488 * * *$ & 0.000 \\
DINV & $25.340 * * *$ & 0.000 & & $347.078 * * *$ & 0.000 \\
FDI & $39.600 * * *$ & 0.000 & & $235.568 * * *$ & 0.000 \\
POP & $10.34 * * *$ & 0.000 & & $208.422 * * *$ & 0.000 \\
\hline
\end{tabular}

*** $1 \%$ significant level of nonstationary series for the CADF test is not rejected at level for EFP and EOS at all levels of significance, meanwhile the null hypothesis of homogeneous nonstationary series for the CIPS test is rejected at level for the two variables. At first difference, we reject the null hypothesis of both the CIPS and CADF tests. This implies that EFP and EOS are stationary at first difference. In the same light, we fail to reject the null hypothesis of the CIPS test for DINV and POP thus we concluded that they are not stationary at level. At first difference, the null hypothesis of both the CIPS and CADF tests are rejected for both DINV and POP implying that these variables are stationary at first difference. Equally, GDP, GDP2, GDP3, and FDI indicate the rejection of the null hypothesis of both unit root test. This shows that the variables are stationary at level.

\section{Slope homogeneity and cointegration test}

In the presence of cross-sectional dependence, Breitung (2005) noted that this may imply that countries are having economic development similarities and as such determining cross-sectional heterogeneity is important otherwise the estimates will be untrustworthy. The Pesaran and Yamagatta (2008) slope homogeneity test is employed in this study. The results of the slope homogeneity test presented in Table 6 indicates that both the EOS and the EF models reject the null hypothesis of slope homogeneity for both test statistics at the $1 \%$ level of significance. This shows that there is the existence of slope heterogeneity.

For cointegration, since there is the strong presence of cross sectional dependence, we only make use of a second generation cointegration test that accounts for cross sectional dependence. The result of the Westerlund (2007) second generation test presented in Table 6 indicates that group and panel test statistics are able to reject the null hypothesis at

Table 5 Panel unit root test

\begin{tabular}{|c|c|c|c|c|c|c|c|}
\hline \multirow{2}{*}{$\begin{array}{l}\text { Test } \\
\text { Significant level }\end{array}$} & \multicolumn{3}{|l|}{ CADF } & \multicolumn{3}{|l|}{ CIPS } & \multirow[t]{3}{*}{ Decision } \\
\hline & $10 \%$ & $5 \%$ & $1 \%$ & $10 \%$ & $5 \%$ & $1 \%$ & \\
\hline Critical values & -2.490 & -2.540 & -2.630 & -2.490 & -2.540 & -2.630 & \\
\hline & Level & First difference & Level & First difference & & & \\
\hline EFP & -2.391 & $-3.368 * * *$ & -2.930 & $-5.019 * * *$ & $\mathrm{I}(1)$ & & \\
\hline EOS & -2.456 & $-3.488 * * *$ & -2.835 & $-4.985 * * *$ & $\mathrm{I}(1)$ & & \\
\hline GDP & $-2.990 * * *$ & - & $-3.722 * * *$ & - & $\mathrm{I}(0)$ & & \\
\hline GDP2 & $-3.378 * * *$ & - & $-3.971 * * *$ & - & $\mathrm{I}(0)$ & & \\
\hline GDP3 & $-3.413 * * *$ & - & $-4.186^{* * *}$ & - & $\mathrm{I}(0)$ & & \\
\hline DINV & $-2.658 * * *$ & - & -2.388 & $-4.143 * * *$ & $\mathrm{I}(1)$ & & \\
\hline FDI & $-2.534^{*}$ & - & $-3.277 * * *$ & - & $\mathrm{I}(0)$ & & \\
\hline POP & $-3.723 * * *$ & - & -2.043 & -2.519 & $\mathrm{I}(1)$ & & \\
\hline
\end{tabular}

$C A D F$, cross-sectional augmented Dickey fuller; CIPS, cross-sectional Im Pesaran and Shin. *10\% significant level; ***1\% significant level 


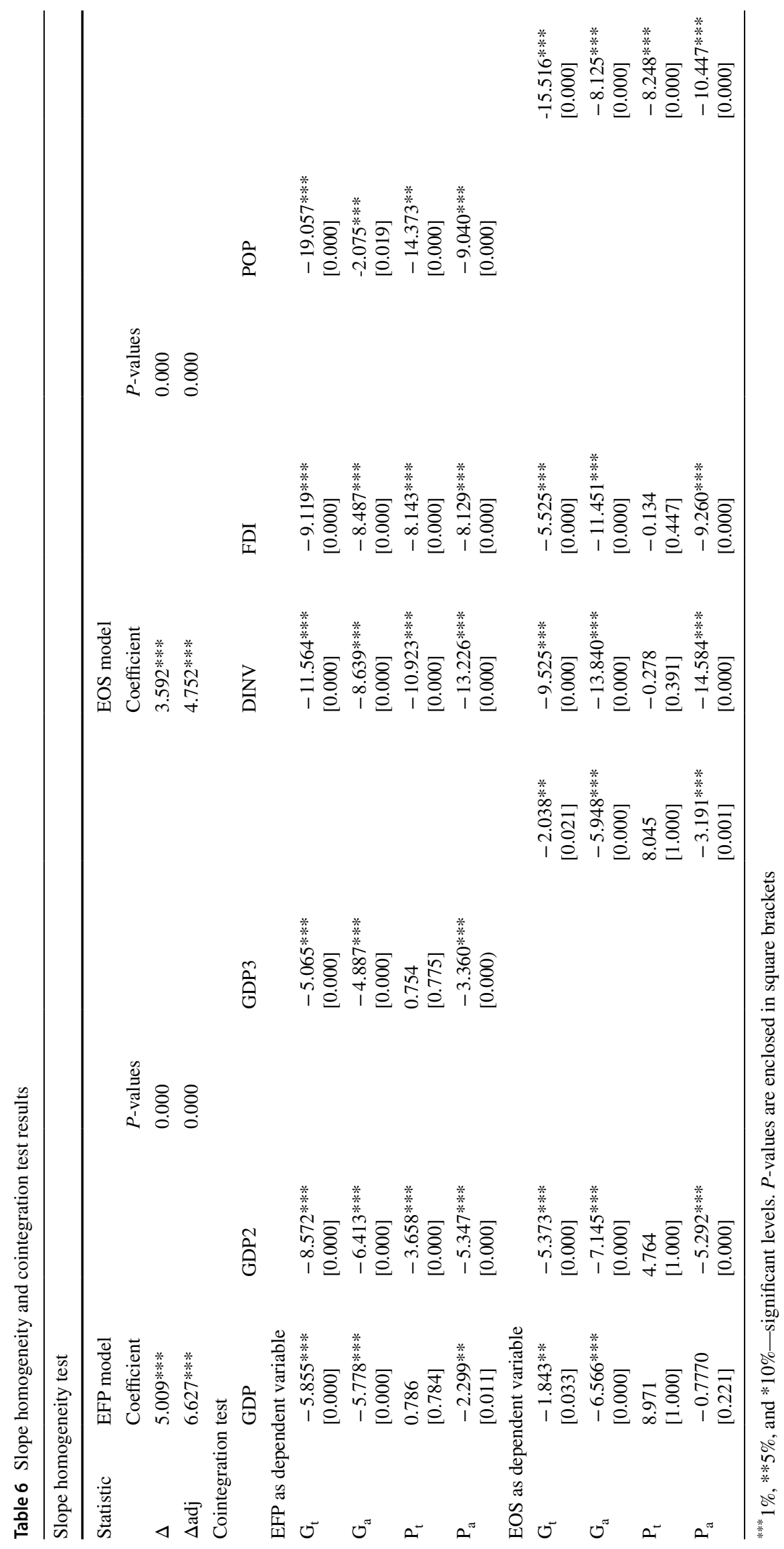


different significant levels (1\% and 5\%) for the ecological footprint and ecological overshoot models. Specifically, the ecological footprint model indicates that all the group test $\left(G_{a}, G_{t}\right)$ and the panel test $\left(P_{a}, P_{t}\right)$ confirms rejection of the null hypothesis of no cointegration between EF and GDP2, DINV, FDI, and POP. For GDP and GDP3, cointegration is confirmed for all test statistics except the $\mathrm{P}_{\mathrm{t}}$ test statistics. This implies the strong presence of cointegration between EF and the variables of interest. Similarly, the cointegration relation between EOS and the different variables of the studies shows that the two group test statistics validates the presence of cointegration for all the different variables. On the other hand, the panel test $\mathrm{P}_{\mathrm{t}}$ confirms cointegration only for POP while $\mathrm{P}_{\mathrm{a}}$ statistics rejects the null hypothesis for no cointegration relation for all variables except GDP.

This result shows the validation of cointegration for most test statistics and as such we conclude that there is strong evidence of a long-run relationship between the variables of the studies. With the confirmation of cointegration, we proceed to empirically estimate our different models.

\section{Estimated results}

Tables 7 and 8 present the outcomes of the two basic models of our dualistic approach analyses. As highlighted above, the validation of a dualistic approach to environmental degradation analyses will depend on the different signs of GDP per capital variable in its different forms. We first start by estimating a linear model for both the EF and EOS equations. As indicated in models 1 and 7 in Tables 7 and 8, respectively, GDP has a positive sign in 1 and a negative sign in 7 showing that increase growth in the world increases pollution (demand side) and reduces available biocapacity (supply side) of the society at large. This result affirms a dualistic outcome for the linear relationship between growth in income and the demand/supply side environmental analyses. In order to empirically ascertain the dualistic model of the U-shaped EKC hypothesis, we estimate models 2 and 8 without any explanatory variable. The results from model 2 indicate a positive sign for GDP and a negative sign for GDP2 thereby validating the U-shape EKC hypothesis which is in line with the findings of authors like Ahmad et al. (2020) and Naqvi et al. (2020) for high-income countries, Khan and Eggoh (2020) and Beyene and Kotosz (2019) for low-income countries, meanwhile the outcome contradicts Jard $o ́ \mathrm{n}$ et al. (2017). For the supply side outcome shown in model 8 , GDP is seen to have a negative sign while GDP2 shows a positive sign on ecological overshoot. This indicates a supply side inverted bell shape for EOS. This result confirms our a priori hypothesis of a dualistic EKC hypothesis between EF and EOS. This shows that on the demand side, as per capital income increases within countries, there is an initial increase in environmental pollution up to a certain marginal level wherein, increase in per capita income
Table 7 Estimated results for the demand side

\begin{tabular}{|c|c|c|c|c|c|c|}
\hline EFP & 1 & 2 & 3 & 4 & 5 & 6 \\
\hline 1. EFP & $\begin{array}{l}-0.1965^{* * *} \\
{[0.020]}\end{array}$ & $\begin{array}{l}-0.2076^{* * *} \\
{[0.021]}\end{array}$ & $\begin{array}{l}-0.2167 * * * \\
{[0.023]}\end{array}$ & $\begin{array}{l}-0.2092 * * * \\
{[0.023]}\end{array}$ & $\begin{array}{l}-0.2227 * * * \\
{[0.024]}\end{array}$ & $\begin{array}{l}-0.2532 * * * \\
{[0.026]}\end{array}$ \\
\hline GDP & $\begin{array}{l}0.0230 * * * \\
{[0.004]}\end{array}$ & $\begin{array}{l}0.0277 * * * \\
{[0.005]}\end{array}$ & $\begin{array}{l}0.0333 * * * \\
{[0.010]}\end{array}$ & $\begin{array}{l}0.0258^{* *} \\
{[0.010]}\end{array}$ & $\begin{array}{l}0.0202 * \\
{[0.011]}\end{array}$ & $\begin{array}{l}0.0301^{*} \\
{[0.015]}\end{array}$ \\
\hline GDP2 & & $\begin{array}{l}-0.0012 \\
{[0.135]}\end{array}$ & $\begin{array}{l}-0.0041 \\
{[0.003]}\end{array}$ & $\begin{array}{l}-0.0033 \\
{[0.004]}\end{array}$ & $\begin{array}{l}-0.0030 \\
{[0.004]}\end{array}$ & $\begin{array}{l}-0.0049 \\
{[0.005]}\end{array}$ \\
\hline GDP3 & & & $\begin{array}{l}0.0003 \\
{[0.001]}\end{array}$ & $\begin{array}{l}0.0003 \\
{[0.001]}\end{array}$ & $\begin{array}{l}0.0006 \\
{[0.001]}\end{array}$ & $\begin{array}{l}0.0007 \\
{[0.001]}\end{array}$ \\
\hline DINV & & & & $\begin{array}{l}-0.0019 \\
{[0.007]}\end{array}$ & $\begin{array}{l}-0.0054 \\
{[0.008]}\end{array}$ & $\begin{array}{l}-0.0078 \\
{[0.008]}\end{array}$ \\
\hline FDI & & & & & $\begin{array}{l}0.0040 \\
{[0.006]}\end{array}$ & $\begin{array}{l}0.0051 \\
{[0.006]}\end{array}$ \\
\hline POP & & & & & & $\begin{array}{l}-0.3796^{*} \\
{[0.149]}\end{array}$ \\
\hline cons & $\begin{array}{l}0.1021 * * * \\
{[0.017]}\end{array}$ & $\begin{array}{l}0.1026 * * * \\
{[0.018]}\end{array}$ & $\begin{array}{l}0.0997 * * * \\
{[0.018]}\end{array}$ & $\begin{array}{l}0.0936^{* * * *} \\
{[0.017]}\end{array}$ & $\begin{array}{l}0.1041 * * * \\
{[0.023]}\end{array}$ & $\begin{array}{l}0.1261 * * * \\
{[0.029]}\end{array}$ \\
\hline obs & 2180 & 2180 & 2180 & 2180 & 2180 & 2180 \\
\hline F-statistics & $\begin{array}{l}2.16 \\
(0.00)\end{array}$ & $\begin{array}{l}1.86 \\
(0.00)\end{array}$ & $\begin{array}{l}1.60 \\
(0.00)\end{array}$ & $\begin{array}{l}1.59 \\
(0.00)\end{array}$ & $\begin{array}{l}1.54 \\
(0.00)\end{array}$ & $\begin{array}{l}1.54 \\
(0.00)\end{array}$ \\
\hline Rsqur & 0.72 & 0.68 & 0.65 & 0.60 & 0.55 & 0.49 \\
\hline CD-stats & $\begin{array}{l}14.90 \\
(0.000)\end{array}$ & $\begin{array}{l}14.00 \\
(0.000)\end{array}$ & $\begin{array}{l}13.08 \\
(0.000)\end{array}$ & $\begin{array}{l}12.33 \\
(0.000)\end{array}$ & $\begin{array}{l}11.79 \\
(0.000)\end{array}$ & $\begin{array}{l}11.92 \\
(0.000)\end{array}$ \\
\hline
\end{tabular}

$* * * 1 \%$, **5\%, and *10\%-significant levels. $P$-values are enclosed in parentheses. Standard errors are enclosed in square brackets 
Table 8 Estimated results for the supply side

\begin{tabular}{|c|c|c|c|c|c|c|}
\hline EOS & 7 & 8 & 9 & 10 & 11 & 12 \\
\hline 1. EOS & $\begin{array}{l}-0.2281 * * * \\
{[0.023]}\end{array}$ & $\begin{array}{l}-0.2383 * * * \\
{[0.024]}\end{array}$ & $\begin{array}{l}-0.2421 * * *[ \\
0.024]\end{array}$ & $\begin{array}{l}-0.2350 * * *[ \\
0.024]\end{array}$ & $\begin{array}{l}-0.2535 \text { *** } \\
{[0.025]}\end{array}$ & $\begin{array}{l}-0.2829 * * *[ \\
0.027]\end{array}$ \\
\hline GDP & $\begin{array}{l}-0.0165 * * *[ \\
0.004]\end{array}$ & $\begin{array}{l}-0.0256 * * *[ \\
0.006]\end{array}$ & $\begin{array}{l}-0.0306 *[ \\
0.011]\end{array}$ & $\begin{array}{l}-0.0115[ \\
0.011]\end{array}$ & $\begin{array}{l}-0.0062[ \\
0.011]\end{array}$ & $\begin{array}{l}-0.0152[ \\
0.015]\end{array}$ \\
\hline GDP2 & & $\begin{array}{l}0.0029 * *[ \\
0.002]\end{array}$ & $\begin{array}{l}0.0028[ \\
0.004]\end{array}$ & $\begin{array}{l}0.0018[ \\
0.004]\end{array}$ & $\begin{array}{l}0.0002[ \\
0.004]\end{array}$ & $\begin{array}{l}0.0043[ \\
0.006]\end{array}$ \\
\hline GDP3 & & & $\begin{array}{l}-0.0001[ \\
0.001]\end{array}$ & $\begin{array}{l}-0.0002[ \\
0.001]\end{array}$ & $\begin{array}{l}-0.0001[ \\
0.001]\end{array}$ & $\begin{array}{l}-0.0007[ \\
0.001]\end{array}$ \\
\hline DINV & & & & $\begin{array}{l}-0.0003[ \\
0.006]\end{array}$ & $\begin{array}{l}-0.0002[ \\
0.007]\end{array}$ & $\begin{array}{l}-0.0025[ \\
0.008]\end{array}$ \\
\hline FDI & & & & & $\begin{array}{l}-0.0015[ \\
0.005]\end{array}$ & $\begin{array}{l}-0.0014[ \\
0.005]\end{array}$ \\
\hline POP & & & & & & $\begin{array}{l}0.1787[ \\
0.220]\end{array}$ \\
\hline cons & $\begin{array}{l}-0.0701 * * *[ \\
0.018]\end{array}$ & $\begin{array}{l}-0.0732 * * *[ \\
0.018]\end{array}$ & $\begin{array}{l}-0.0735 * * *[ \\
0.018]\end{array}$ & $\begin{array}{l}-0.0680 * * *[ \\
0.016]\end{array}$ & $\begin{array}{l}-0.0674 * * *[ \\
0.021]\end{array}$ & $\begin{array}{l}-0.0748 * * *[ \\
0.021]\end{array}$ \\
\hline obs & 2180 & 2180 & 2180 & 2180 & 2180 & 2180 \\
\hline F-statistics & $\begin{array}{l}2.34 \\
(0.00)\end{array}$ & $\begin{array}{l}2.02 \\
(0.00)\end{array}$ & $\begin{array}{l}1.71 \\
(0.00)\end{array}$ & $\begin{array}{l}1.68 \\
(0.00)\end{array}$ & $\begin{array}{l}1.64 \\
(0.00)\end{array}$ & $\begin{array}{l}1.56 \\
(0.00)\end{array}$ \\
\hline$R$ squr & 0.71 & 0.66 & 0.64 & 0.58 & 0.53 & 0.49 \\
\hline CD-stats & $\begin{array}{l}6.59 \\
(0.000)\end{array}$ & $\begin{array}{l}5.88 \\
(0.000)\end{array}$ & $\begin{array}{l}6.16 \\
(0.000)\end{array}$ & $\begin{array}{l}4.94 \\
(0.000)\end{array}$ & $\begin{array}{l}4.28 \\
(0.000)\end{array}$ & $\begin{array}{l}4.06 \\
(0.000)\end{array}$ \\
\hline
\end{tabular}

*** $1 \%, * * 5 \%$, and $* 10 \%$-significant levels. $P$-values are enclosed in parentheses. Standard errors are enclosed in brackets

leads to ecological improvement. In the same vein, on the supply side, the outcome implies that as income per capita increases, there is an initial decrease in available ecological biocapacity up to a certain marginal level before it starts improving.

In order to examine the $\mathrm{N}$-shaped environmental Kuznets curve hypothesis and its proposed dualistic relation, we estimate Eqs. (3) and (9) without any explanatory variable in Tables 7 and 8, respectively. The outcome shows that for the demand side, the existence of the N-shaped EKC hypothesis is approved for our global sample since the coefficient of GDP, GDP2, and GDP3 are positive, negative, and positive, respectively. For the supply side, an inverted $\mathrm{N}$-shaped EKC hypothesis is validated for the general sample since the signs of GDP and its corresponding polynomial values alternate that is negative, positive, and negative. This outcome reaffirms the dualistic approach to environmental quality analyses proposed in this study, and it is in line with our a priori expectation.

For robustness of the results, we estimate the baseline model with the inclusion of other explanatory variables systematically for the demand side analyses $(4,5$, and 6$)$ and the supply side analyses $(10,11,12)$. The outcome indicates that the signs of the income per capital remain consistently the same as in the baseline model with the inclusion of different explanatory variables both for the ecological footprint models and the ecological overshoot models. Equally, the constants of the EF-estimated model are all positive whereas those of the EOS-estimated models are all negative, which shows that with a growth in income set at zero, other factors will significantly increase EF and equally decrease EOS. This reaffirms the dualistic nature of outcome between the traditional demand side analyses and the newly proposed supply side analyses in this study.

Concerning the goodness of fit of the estimated models, all the F-statistics of the different models estimated for the EF (1 to 6) and those estimated for the EOS (7-12) are all significant at $1 \%$. This shows global fitness of all the models. Equally, cross-sectional dependence is confirmed in all equations since all the $\mathrm{CD}$-statistics rejects the null hypothesis of no cross-sectional dependence.

In order to capture disparity of outcome that may occur due to income-level disparity, and to equally make comparative analyses, we re-examine the dualistic U-shaped and $\mathrm{N}$-shaped environmental Kuznets curve hypothesis for lower-income countries (LIC), lower middle-income countries (LMIC), upper middle-income countries (UMIC), and high-income countries (HIC). The outcome of the income-level analysis for the dualistic approach proposed in this study is presented in Table 9 for the EF analyses and Table 10 for the EOS analyses. From the results of the EF (demand side) estimate, the U-shaped EKC hypothesis is validated at all income levels (LIC, LMIC, UMIC, HIC), but comparatively, this results seems to show less significances 
Table 9 Income-level estimations for the demand side

\begin{tabular}{|c|c|c|c|c|c|c|c|c|}
\hline Models & $\begin{array}{l}13 \\
\text { LIC }\end{array}$ & $\begin{array}{l}14 \\
\text { LMIC }\end{array}$ & $\begin{array}{l}15 \\
\text { UMIC }\end{array}$ & $\begin{array}{l}16 \\
\text { HIC }\end{array}$ & $\begin{array}{l}17 \\
\text { LIC }\end{array}$ & $\begin{array}{l}18 \\
\text { LMIC }\end{array}$ & $\begin{array}{l}19 \\
\text { UMIC }\end{array}$ & $\begin{array}{l}20 \\
\text { HIC }\end{array}$ \\
\hline 1. EFP & $\begin{array}{l}-0.2003 * * *[ \\
0.054]\end{array}$ & $\begin{array}{l}-0.1701 * * *[ \\
0.042]\end{array}$ & $\begin{array}{l}-0.2540 * * *[ \\
0.035]\end{array}$ & $\begin{array}{l}-0.1989 * * *[ \\
0.042]\end{array}$ & $\begin{array}{l}-0.2209 * * *[ \\
0.060]\end{array}$ & $\begin{array}{l}-0.1790 * * *[ \\
0.048]\end{array}$ & $\begin{array}{l}-0.2651 * * *[ \\
0.037]\end{array}$ & $\begin{array}{l}-0.1950 * * *[ \\
0.043]\end{array}$ \\
\hline GDP & $\begin{array}{l}0.0077[ \\
0.006]\end{array}$ & $\begin{array}{l}0.0252 * *[ \\
0.009]\end{array}$ & $\begin{array}{l}0.0202 * *[ \\
0.008]\end{array}$ & $\begin{array}{l}0.0589 * * *[ \\
0.015]\end{array}$ & $\begin{array}{l}0.0182 \mathrm{y}[ \\
0.007]\end{array}$ & $\begin{array}{l}0.0026[ \\
0.014]\end{array}$ & $\begin{array}{l}0.0300[ \\
0.023]\end{array}$ & $\begin{array}{l}0.0907 * * *[ \\
0.025]\end{array}$ \\
\hline GDP2 & $\begin{array}{l}-0.0004[ \\
0.001]\end{array}$ & $\begin{array}{l}-0.0030 * *[ \\
0.001]\end{array}$ & $\begin{array}{l}-0.0004[ \\
0.001]\end{array}$ & $\begin{array}{l}-0.0025[ \\
0.004]\end{array}$ & $\begin{array}{l}-0.0042[ \\
0.004]\end{array}$ & $\begin{array}{l}0.0060[ \\
0.005]\end{array}$ & $\begin{array}{l}-0.0018[ \\
0.005]\end{array}$ & $\begin{array}{l}-0.0202 * *[ \\
0.010]\end{array}$ \\
\hline GDP3 & & & & & $\begin{array}{l}0.0006[ \\
0.001]\end{array}$ & $\begin{array}{l}-0.0009[ \\
0.001]\end{array}$ & $\begin{array}{l}-0.0001[ \\
0.001]\end{array}$ & $\begin{array}{l}0.0021[ \\
0.002]\end{array}$ \\
\hline cons & $\begin{array}{l}0.0247 * * *[ \\
0.009]\end{array}$ & $\begin{array}{l}0.0464 * * *[ \\
0.015]\end{array}$ & $\begin{array}{l}0.1125^{* * *}[ \\
0.019]\end{array}$ & $\begin{array}{l}0.2296 * * *[ \\
0.004]\end{array}$ & $\begin{array}{l}0.0214^{* *}[ \\
0.009]\end{array}$ & $\begin{array}{l}0.0362 *[ \\
0.0187]\end{array}$ & $\begin{array}{l}0.1153 * * *[ \\
0.018]\end{array}$ & $\begin{array}{l}0.2287 * * *[ \\
0.067]\end{array}$ \\
\hline obs & 420 & 620 & 660 & 480 & 420 & 620 & 660 & 480 \\
\hline F-statistics & $\begin{array}{l}3.62 \\
(0.00)\end{array}$ & $\begin{array}{l}2.46 \\
(0.00)\end{array}$ & $\begin{array}{l}2.49 \\
(0.00)\end{array}$ & $\begin{array}{l}1.62 \\
(0.00)\end{array}$ & $\begin{array}{l}3.30 \\
(0.00)\end{array}$ & $\begin{array}{l}2.40 \\
(0.00)\end{array}$ & $\begin{array}{l}2.18 \\
(0.00)\end{array}$ & $\begin{array}{l}1.36 \\
(0.02)\end{array}$ \\
\hline$R$ squr & 0.52 & 0.62 & 0.62 & 0.71 & 0.48 & 0.55 & 0.58 & 0.69 \\
\hline CD-stats & $\begin{array}{l}1.90 \\
(0.057)\end{array}$ & $\begin{array}{l}3.47 \\
(0.001)\end{array}$ & $\begin{array}{l}5.48 \\
(0.000)\end{array}$ & $\begin{array}{l}3.75 \\
(0.000)\end{array}$ & $\begin{array}{l}1.32 \\
(0.187)\end{array}$ & $\begin{array}{l}4.08 \\
(0.00)\end{array}$ & $\begin{array}{l}4.44 \\
(0.000)\end{array}$ & $\begin{array}{l}4.51 \\
(0.000)\end{array}$ \\
\hline
\end{tabular}

$* * * 1 \%, * * 5 \%$, and $* 10 \%$ - significant levels. $P$-values are enclosed in parentheses. Standard errors are enclosed in square brackets

Table 10 Income-level estimations for the supply side

\begin{tabular}{|c|c|c|c|c|c|c|c|c|}
\hline Models & $\begin{array}{l}21 \\
\text { LIC }\end{array}$ & $\begin{array}{l}22 \\
\text { LMIC }\end{array}$ & $\begin{array}{l}23 \\
\text { UMIC }\end{array}$ & $\begin{array}{l}24 \\
\text { HIC }\end{array}$ & $\begin{array}{l}25 \\
\text { LIC }\end{array}$ & $\begin{array}{l}26 \\
\text { LMIC }\end{array}$ & $\begin{array}{l}27 \\
\text { UMIC }\end{array}$ & $\begin{array}{l}28 \\
\text { HIC }\end{array}$ \\
\hline 1. EOS & $\begin{array}{l}-0.2095 * * *[ \\
0.048]\end{array}$ & $\begin{array}{l}-0.2382 * * *[ \\
0.0528]\end{array}$ & $\begin{array}{l}-0.2756 * * *[ \\
0.045]\end{array}$ & $\begin{array}{l}-0.2122 * * *[ \\
0.038]\end{array}$ & $\begin{array}{l}-0.2147 * * *[ \\
0.0494]\end{array}$ & $\begin{array}{l}-0.2511^{* * *}[ \\
0.055]\end{array}$ & $\begin{array}{l}-0.2716^{* * *}[ \\
0.046]\end{array}$ & $\begin{array}{l}-0.2139 * * *[ \\
0.040]\end{array}$ \\
\hline GDP & $\begin{array}{l}0.0005[ \\
0.003]\end{array}$ & $\begin{array}{l}-0.0233^{* *}[ \\
0.011]\end{array}$ & $\begin{array}{l}-0.0183 * *[ \\
0.008]\end{array}$ & $\begin{array}{l}-0.0613^{* * *}[ \\
0.022]\end{array}$ & $\begin{array}{l}0.0061[ \\
0.011]\end{array}$ & $\begin{array}{l}0.0051[ \\
0.009]\end{array}$ & $\begin{array}{l}-0.0183[ \\
0.022]\end{array}$ & $\begin{array}{l}-0.080^{* *}[ \\
0.037]\end{array}$ \\
\hline GDP2 & $\begin{array}{l}-0.00004[ \\
0.001]\end{array}$ & $\begin{array}{l}0.0030 *[ \\
0.002]\end{array}$ & $\begin{array}{l}0.0010[ \\
0.001]\end{array}$ & $\begin{array}{l}0.0082[ \\
0.006]\end{array}$ & $\begin{array}{l}-0.0010[ \\
0.004]\end{array}$ & $\begin{array}{l}-0.0078^{*}[ \\
0.004]\end{array}$ & $\begin{array}{l}0.0015[ \\
0.005]\end{array}$ & $\begin{array}{l}0.0214[ \\
0.014]\end{array}$ \\
\hline GDP3 & & & & & $\begin{array}{l}-0.00004[ \\
0.0004]\end{array}$ & $\begin{array}{l}0.0012 *[ \\
0.001]\end{array}$ & $\begin{array}{l}-0.0002[ \\
0.0004]\end{array}$ & $\begin{array}{l}-0.0017[ \\
0.002]\end{array}$ \\
\hline cons & $\begin{array}{l}-0.0139 * * *[ \\
0.006]\end{array}$ & $\begin{array}{l}-0.0499 * * *[ \\
0.018]\end{array}$ & $\begin{array}{l}-0.0860 * * *[ \\
0.018]\end{array}$ & $\begin{array}{l}-0.1376^{*}[ \\
0.073]\end{array}$ & $\begin{array}{l}-0.0148 * * *[ \\
0.006]\end{array}$ & $\begin{array}{l}-0.0465 * * *[ \\
0.018]\end{array}$ & $\begin{array}{l}-0.0867 * * *[ \\
0.018]\end{array}$ & $\begin{array}{l}-0.1416^{*}[ \\
0.075]\end{array}$ \\
\hline obs & 420 & 620 & 660 & 480 & 420 & 620 & 660 & 480 \\
\hline F-statistics & $\begin{array}{l}1.67 \\
(0.00)\end{array}$ & $\begin{array}{l}2.08 \\
(0.00)\end{array}$ & $\begin{array}{l}2.90 \\
(0.00)\end{array}$ & $\begin{array}{l}1.80 \\
(0.00)\end{array}$ & $\begin{array}{l}1.51 \\
(0.00)\end{array}$ & $\begin{array}{l}1.83 \\
(0.00)\end{array}$ & $\begin{array}{l}2.39 \\
(0.00)\end{array}$ & $\begin{array}{l}1.52 \\
(0.00)\end{array}$ \\
\hline$R$ squr & 0.70 & 0.66 & 0.58 & 0.69 & 0.67 & 0.62 & 0.56 & 0.66 \\
\hline CD-stats & $\begin{array}{l}0.596 \\
(0.596)\end{array}$ & $\begin{array}{l}1.63 \\
(0.103)\end{array}$ & $\begin{array}{l}1.00 \\
(0.317)\end{array}$ & $\begin{array}{l}3.50 \\
(0.001)\end{array}$ & $\begin{array}{l}-0.31 \\
(0.758)\end{array}$ & $\begin{array}{l}2.41 \\
(0.016)\end{array}$ & $\begin{array}{l}0.70 \\
(0.485)\end{array}$ & $\begin{array}{l}4.06 \\
(0.000)\end{array}$ \\
\hline
\end{tabular}

*** $1 \%, * * 5 \%$, and $* 10 \%$ - significant levels. $P$-values are enclosed in parentheses. Standard errors are enclosed in square brackets

for LIC and turns to be more significant for LMIC where both the quadratic and the linear coefficients are seen to be significant at $5 \%$ level of significance. Equally, crosssectional dependence is confirmed in all the subpanels. For the $\mathrm{N}$-shaped baseline income-level comparison presented in columns 17, 18, 19, and 20, LIC and HIC within the panel indicate sufficient information to validate the $\mathrm{N}$-shaped EKC hypothesis, but this result is seemingly more significant for HIC. However, for LMIC and UMIC estimates, the $\mathrm{N}$-shaped hypothesis is not valid. The results show that LMIC do not commit resources to ameliorate the quality of the environment while UMIC experienced environmental amelioration through decrease in EF and will rarely return to environmental degradation as proposed by the $\mathrm{N}$-shaped EKC. The nonvalidity of the model for LMIC and UMIC can be due to the fact that the economies are at the lower end of the income group, where less focus is on environmental amelioration. 
As shown by the supply side income-level analyses in Table 10, for the baseline result of the corresponding dualistic U-shaped EKC, the outcome affirms the existence of the U-shaped dual EKC as proposed in this study for LMIC, UMIC, and HIC. But this outcome is not true for LIC which shows an initial positive value and a negative value for the quadratic term. This result validates a dualistic dual outcome from the primal outcome obtained for LMIC, UMIC, and HIC for the demand side analyses above. For the inverted $\mathrm{N}$-shaped analyses for different income levels, models 25 to 28 indicate that an inverted $\mathrm{N}$ shape is only validated for the UMIC and the HIC. But the outcome is more significant for HIC. This result highlights the importance of cross-sectional dependence in the analyses of the dualistic relation in environmental quality analyses, since the dual-primal relation is more validated for high-income countries and the $\mathrm{CD}$-test statics is only highly significant for HIC. The nonconsideration of the high-income countries which are seemingly the highest polluters in the world today will bias the estimate of all the subpanels and lead to the nonvalidation of the $\mathrm{N}$-shaped dualistic EKC hypothesis.

In order to ascertain the robustness of the outcome obtained from this study, we conduct second-generation unit root test on all the 28 estimated models. The results obtained from the CADF and CIPS second-generation unit root test presented in Table 11 indicate that the null hypothesis of panel residuals containing unit root is rejected for all the 28 models for the CADF and CIPS tests. This shows that our estimated results are stable and valid for all the inferences made.

\section{Conclusion and policy implications}

In this study, we sought to present a new approach of analyzing the nexus between environmental degradation and income in the world. On the one hand, we analyzed the demand side of human activities from nature with the use of ecological footprint and on the other hand, nature supply side was analyzed with the use of nature ecological overshoot. We employed geometry to present our basic dualistic analyses; meanwhile, mathematical demonstration is employed to elucidate the expected dualistic model. To test our proposed dualistic model, we used a balanced panel of 109 countries from 1995 to 2016 . Given the level of globalization in the world today, we first test our data for cross-sectional dependence using the Pesaran $(2004,2015)$ cross-sectional dependence test in order to choose appropriate test and estimation techniques. With the confirmation of cross-sectional dependence in our data, we employed second-generation tests for unit root, cointegration, and slope homogeneity that account for cross-sectional dependence.

Our adopted estimation technique is the dynamic common correlation technique proposed by Chudik and Pesaran (2015) that accounts for cross-sectional dependence within panels. From the different results obtained, there is clear evidence of the existence of our proposed dual U-shaped and dual N-shaped EKC. Equally, when we separate our panel into different income levels, the dual U-shaped EKC hypothesis is validated for all our subpanels but for LIC. For the income-level dual N-shaped EKC hypothesis, the dual $\mathrm{N}$ shape is confirmed principally in HIC. Based on these outcomes, this study proposes the following recommendations:

The equilibrium or maximum absorbable level of pollution where biocapacity equals the pollution level should be
Table 11 Panel residual unit root test

\begin{tabular}{|c|c|c|c|c|c|}
\hline $\begin{array}{l}\text { Residuals equa- } \\
\text { tions }\end{array}$ & CADF & CIPS & $\begin{array}{l}\text { Residuals equa- } \\
\text { tions }\end{array}$ & CADF & CIPS \\
\hline $\mathrm{R} 1$ & $-2.938 * * *$ & $-3.856^{* * *}$ & $\mathrm{R} 15$ & $-2.920 * * *$ & $-3.752 * * *$ \\
\hline R2 & $-3.035^{* * *}$ & $-3.921 * * *$ & $\mathrm{R} 16$ & $-2.955 * * *$ & $-3.851 * * *$ \\
\hline R3 & $-3.082 * * *$ & $-4.047 * * *$ & $\mathrm{R} 17$ & $-2.999 * * *$ & $-4.651 * * *$ \\
\hline R4 & $-3.171 * * *$ & $-4.257 * * *$ & $\mathrm{R} 18$ & $-2.975 * * *$ & $-3.661 * * *$ \\
\hline R5 & $-3.124 * * *$ & $-4.365^{* * *}$ & R19 & $-2.948 * * *$ & $-3.835^{* * *}$ \\
\hline R6 & $-3.045^{* * *}$ & $-4.326 * * *$ & $\mathrm{R} 20$ & $-2.820 * * *$ & $-3.854 * * *$ \\
\hline R7 & $-2.873 * * *$ & $-4.104 * * *$ & $\mathrm{R} 21$ & $-3.203 * * *$ & $-4.557 * * *$ \\
\hline R8 & $-2.957 * * *$ & $-4.086^{* * *}$ & $\mathrm{R} 22$ & $-3.151 * * *$ & $-3.969 * * *$ \\
\hline R9 & $-3.081 * * *$ & $-4.178 * * *$ & $\mathrm{R} 23$ & $-2.920 * * *$ & $-3.787 * * *$ \\
\hline R10 & $-3.125^{* * *}$ & $-4.285^{* * *}$ & $\mathrm{R} 24$ & $-2.929 * * *$ & $-3.980 * * *$ \\
\hline R11 & $-3.144 * * *$ & $-4.378 * * *$ & $\mathrm{R} 25$ & $-3.278 * * *$ & $-4.856^{* * *}$ \\
\hline R12 & $-3.159 * * *$ & $-4.570 * * *$ & R26 & $-3.014 * * *$ & $-3.542 * * *$ \\
\hline R13 & $-3.064 * * *$ & $-4.508 * * *$ & $\mathrm{R} 27$ & $-3.026^{* * *}$ & $-3.855^{* * *}$ \\
\hline R14 & $-3.024 * * *$ & $-3.831 * * *$ & $\mathrm{R} 28$ & $-2.919 * * *$ & $-3.924 * * *$ \\
\hline
\end{tabular}


determined both at individual country level and the world at large. This will encourage countries to clean their environment and stay below this equilibrium point in order to avoid future environmental disasters. Countries should put in place pollution cleaning policies that can prevent them from reaching their overshoot day. This should be a principal task for international organizations like the United Nations.

Since the LIC fails to validate the dual EKC hypothesis, this indicates the inability for the LIC to put in place appropriate policies to ensure that the composition and technique effect of growth are unable to overcome scale effect. Therefore, LIC needs to enhance policies like environmental regulations (pollution tax for example) and the diffusion and relocation of modern technology in a way that the technical effect can be improved and environmental pollution reduced.

Since the dual N shape is principally confirmed in highincome countries, policy makers in these countries should not relax environmentally friendly policies when growth start enhancing, since relaxing environmental policies can lead to a scenario where the scale effects of growth will outweigh the composition and technique effect, thus leading to deterioration in the environment.

Advanced economies should aid less-developed economies with new and efficient abatement technologies that will help these economies better clean their environment. The developed economies should equally give ample financial aid to developing and less industrialized countries especially those with high available biocapacity in order for these economies to adopt cleaner and environment-friendly industrialization policies, like the encouragement of renewable energy sources.

The enhancement of data collection techniques in middleincome and low-income countries and the consideration of countries with limited information about environmental degradation are necessary, in order to obtain accurate information with respect to biocapacity and rate of environmental degradation. The availability of adequate information on biocapacity and the rate of environmental degradation will help policymakers to better handle the problem of environmental pollution in a global and holistic manner and promote interstate cooperation in such key issues that affect humanity.

This study has a given number of limitations. Firstly, the time period runs from 1995 to 2016 due to limited data. Data on the global footprint network for ecological footprint and biocapacity always has a 4-year lag, making the data not so current. Equally, many countries do not have data on EF and biocapacity. The availability of data for all countries can lead to more robust and holistic analyses that will produce a more robust comparative analysis of the dualistic EKC proposed in this study.

We equally recommend the extension of such dualistic investigation within different countries in the world and within different trade blocs since some specificities from individual countries and regional blocs can influence the outcome of the dual EKC.

Author contribution GDD participated in the conceptualization, writing, analyses, and interpretation in the manuscript. DCF participated in the conceptualization, writing, editing, and interpretation of the manuscript. DEA reading and editing.

Data availability The data sets used and/or analyzed during the current study are available from the corresponding author on request.

\section{Declarations}

Ethics approval and consent to participate Not applicable.

Consent for publication Not applicable.

Competing interests The authors declare no competing interests.

\section{References}

Abbasi MA, Parveen S, Khan S, Kamal MA (2020) Urbanization and energy consumption effects on carbon dioxide emissions: evidence from Asian-8 countries using panel data analysis. Environ Sci Pollut Res 27:18029-18043. https://doi.org/10.1007/ s11356-020-08262-w

Ahmad M, Jiang P, Majeed A, Raza MY (2020) Does financial development and foreign direct investment improve environmental quality? Evidence from belt and road countries. Environ Sci Pollut Res 27:1-16

Akbostancı E, Türüt-Aşık S, Tunç Gİ (2009) The relationship between income and environment in Turkey: is there an environmental Kuznets curve? Energy Policy 37(3):861-867

Ali S, Yusop Z, Kaliappan SR, Chin L (2020) Dynamic common correlated effects of trade openness, FDI, and institutional performance on environmental quality: evidence from OIC countries. Environmental Science Pollution Research 27(11671-11682):1-12. https://doi.org/10.1007/s11356-020-07768-7

Allard A, Takman J, Uddin GS, Ahmed A (2018a) The N-shaped environmental Kuznets curve: an empirical evaluation using a panel quantile regression approach. Environ Sci Pollut Res 25:58485861. https://doi.org/10.1007/s11356-017-0907-0

Al-Mulali U, Ozturk I (2016) The investigation of environmental Kuznets curve hypothesis in the advanced economies: the role of energy prices. Renew Sustain Energy Rev 54:1622-1631

Altıntaş H, Kassouri Y (2020) Is the environmental Kuznets curve in Europe related to the per-capita ecological footprint or CO2 emissions? Ecol Indic 113:106187

Álvarez A, Balsalobre D, Cantos JM (2015) Public budget for energy RD\&D and the effects on energy intensity and pollution levels. Environ Sci Pollut Res 22(7):4881-4892

Arain H, Han L, Meo MS (2019) Nexus of FDI, population, energy production, and water resources in South Asia: a fresh insight from dynamic common correlated effects (DCCE). Environ Sci Pollut Res 26(26):27128-27137

Armeanu D, Vintilă G, Andrei JV, Gherghina ŞC, Drăgoi MC, Teodor C (2018) Exploring the link between environmental pollution and economic growth in EU-28 countries: Is there an environmental 
Kuznets curve? PLoS ONE 13:e0195708. https://doi.org/10.1371/ journal.pone. 0195708

Aydin C, Esen Ö, Aydin R (2019) Is the ecological footprint related to the Kuznets curve a real process or rationalizing the ecological consequences of the affluence? Evidence from PSTR approach. Ecol Ind 98:543-555

Bakhsh S, Yin H, Shabir M (2021) Foreign investment and CO2 emissions: do technological innovation and institutional quality matter? Evidence from System GMM Approach. Environ Sci Pollut Res 28(15):19424-19438

Balaguer J, Cantavella M (2016) Estimating the environmental Kuznets curve for Spain by considering fuel oil prices (1874-2011). Ecol Ind 60:853-859

Beckerman W (1992) Economic growth and the environment: whose growth? Whose environment? World Dev 20:481-496

Beyene S, Demissew., and Kotosz, Balázs. (2019) Testing the environmental Kuznets curve hypothesis: an empirical study for East African countries. Int J Environ Stud. https://doi.org/10.1080/ 00207233.2019 .1695445

Breitung J (2005) A parametric approach to the estimation of cointegration vectors in panel data. Econ Review 24:151-173

Chen X, Gong X, Li D, Zhang J (2019) Can information and communication technology reduce $\mathrm{CO} 2$ emission? A quantile regression Analysis. Environ Sci Pollut Res 26(32):32977-32992

Chudik A, Pesaran MH (2015) Common correlated effects estimation of heterogeneous dynamic panel data models with weakly exogenous regressors. Journal of Econometrics 188(2):393-420

De Bruyn SM, van den Bergh JC, Opschoor JB (1998) Economic growth and emissions: reconsidering the empirical basis of environmental Kuznets curves. Ecol Econ 25(2):161-175

Dinda S (2005) A theoretical basis for the environmental Kuznets curve. Ecol Econ 53(3):403-413. https://doi.org/10.1016/j.ecole con.2004.10.007

Dinga G, D., Fonchamnyo, D. C., Nginyu, G. G., and Njuh, C. J. (2020) Short and long run dynamic common correlation effects of external capital inflow on economic growth in SSA countries. Asian J Econ Model 8(4):218-226

Ditzen J (2016) Xtdcce: estimating dynamic common correlation effects in STATA, in United Kingdom Stata Users Group meetings 2016(NO. 08), Stata Users

Dogan E, Turkekul B (2016) $\mathrm{CO}_{2}$ emissions, real output, energy consumption, trade, urbanization and financial development: testing the EKC hypothesis for the USA. Environ Sci Pollut Res 23:1203-1213

Dogan N, Kirikkaleli D (2021) Does gender equality in education matter for environmental sustainability in Sub-Saharan Africa? Environ Sci Pollut Res:1-13. https://doi.org/10.1007/ s11356-021-13452-1

Ehrlich PR, Holden JP (1971) Impact of population growth. Science 171(3977):1212-1217

Friedl B, Getzner M (2003) Determinants of CO2 emissions in a small open economy. Ecol Econ 45:133-148

Gareth J (1968) Unjust enrichment and fiduciarys duty of loyalty. Law Quarterly Review 84:472-502

Grossman GM, Krueger AB (1991) Environmental impacts of north american free trade agreement. National Bureau of Economic Research Working, Paper\#3914 (November)

Grossman GM, Krueger AB (1995) Economic growth and the environment. Q J Econ 110(2):353-377

Haldar A, Sethi N (2021) Effect of institutional quality and renewable energy consumption on $\mathrm{CO} 2$ emissions: an empirical investigation for developing countries. Environ Sci Pollut Res 28(12): 15485-15503

Ibrahim IA, Ötvös T, Gilmanova A, Rocca E, Ghanem C, Wanat M (2021) International Energy Agency. Kluwer Law International BV
Ike GN, Usman O, Sarkodie SA (2020) Testing the role of oil production in the environmental Kuznets curve of oil producing countries: New insights from Method of Moments Quantile Regression. Sci Total Environ 711:135208

IPCC Change, I. C (2014) Mitigation of climate change. Contribution of Working Group III to the Fifth Assessment Report of the Intergovernmental Panel on Climate Change, 1454. J Appl Econ 22(2):265-312

Jardón A, Kuik O, Tol RSJ (2017) Economic growth and carbon dioxide emissions: an analysis of Latin America and the Caribbean. Atmósfera 30(2):87-100

Khan M, Eggoh J (2020) Investigating the direct and indirect linkages between economic development and CO 2 emissions: a PSTR analysis. Environmental Science and Pollution Research, 1-14. Kuznets, S 1955 Economic growth and income inequality. Am Econ Rev 45(1):1-28

Kuznets S (1955) Economic growth and income inequality. Am Econ Rev 1:1-28

McDonald GW, Patterson MG (2004) Ecological footprints and interdependencies of New Zealand regions. Ecol Econ 50(1-2):49-67

Mehmood U (2021) Renewable-non-renewable energy: institutional quality and environment Nexus in South Asian countries. Environ Sci Pollut Res:1-8. https://doi.org/10.1007/s11356-021-12554-0

Naqvi SAA, Shah SAR, Mehdi MA (2020) Revealing empirical association among ecological footprints, renewable energy consumption, real income, and financial development: a global perspective. Environ Sci Pollut Res 27(34):42830-42849

Neal T (2015) Estimating heterogeneous coefficients in panel data models with endogenous regressors and common factors. Workblacking paper

Özokcu S, Özdemir Ö (2017) Economic growth, energy, and environmental Kuznets curve. Renew Sustain Energy Rev 72:639-647

Panayotou T (1993) Empirical tests and policy analysis of environmental degradation at different stages of economic development. Working Paper WP238, Technology and Employment Programme. International Labour Office, Geneva

Pesaran HA (2003) Simple panel unit root test in the presence of cross section dependence University of Cambridge, Faculty of Economics (DAE). Cambridge Working Papers in paper

Pesaran MH (2004) General diagnostic tests for cross section dependence in panels. Cesifo Working Papers 1233:255-260

Pesaran MH (2007) A simple panel unit root test in the presence of cross-section dependence

Pesaran MH (2007) A simple panel unit root test in the presence of cross-section dependence. Journal of applied econometrics 22(2):265-312

Pesaran MH (2015) Testing weak cross sectional dependence in large panels. Economet Rev 34:1089-1117

Pesaran MH, Yamagatta T (2008) Testing slope homogeneity in large panels. Journal of Econometrics 142(2):50-93

Sarafidis V, Wansbeek T (2012) Cross-sectional dependence in panel data analysis. Econom Rev 31(5):483-531

Shafik N, Bandyopadhyay S (1992) Economic growth and environmental quality: time series and cross-country evidence. The World Bank Background paper for the World Development Report, Washington DC

Swamy PAVB (1970) Efficient inference in a random coefficient regression model. Econometrica 38:311-323

Teng JZ, Khan MK, Khan MI, Chishti MZ, Khan MO (2021) Effect of foreign direct investment on $\mathrm{CO} 2$ emission with the role of globalization, institutional quality with pooled mean group panel ARDL. Environ Sci Pollut Res 28(5):5271-5282

Torras M, Boyce JK (1998) Income, inequality, and pollution: a reassessment of the environmental Kuznets curve. Ecol Econ 25(2):147-160 
Ulucak R, Apergis N (2018) Does convergence really matter for the environment? An application based on club convergence and on the ecological footprint concept for the EU countries. Environ Sci Policy 80:21-27

Ulucak R, Bilgili F (2018) A reinvestigation of EKC model by ecological footprint measurement for high, middle and low income countries. J Clean Prod 188:144-157

United Nation (UN) (2015) General assembly. Sustainable development goals. SDGs Transform Our World, 2030

United Nation (UN) (2020) United Nations Environment Programme. Emissions gap report 2020. UNEP, 2020

Wang Z, Ahmed Z, Zhang B, Wang B (2019) The Nexus between urbanization, road infrastructure, and transport energy demand: empirical evidence from Pakistan. Environ Sci Pollut Res 26. https://doi.org/10.1007/s11356-019-06542-8
Wackernagel M (2002) What we use and what we have: ecological footprint and ecological capacity. Redefining Progress, Oakland, USA

Westerlund J (2007) Testing for error correction in panel data. Oxford Bull Econ Stat 69:709-748

World Bank (2019) World development indicators. Retrieved from https://data.worldbank.org/products/wdi

Zhang N, Yu K, Chen Z (2017) How does urbanization affect carbon dioxide emissions? A cross-country panel data analysis. Energy Policy 107:678-687. https://doi.org/10.1016/j.enpol.2017.03.072

Publisher's note Springer Nature remains neutral with regard to jurisdictional claims in published maps and institutional affiliations. 